\title{
Influences on Parents' Decision Making Prior to Youth Sport Program Enrollment
}

\author{
Karl E. Zang
}

Follow this and additional works at: https://researchrepository.wvu.edu/etd

Part of the Sports Studies Commons

\section{Recommended Citation}

Zang, Karl E., "Influences on Parents' Decision Making Prior to Youth Sport Program Enrollment" (2015). Graduate Theses, Dissertations, and Problem Reports. 8153.

https://researchrepository.wvu.edu/etd/8153

This Thesis is protected by copyright and/or related rights. It has been brought to you by the The Research Repository @ WVU with permission from the rights-holder(s). You are free to use this Thesis in any way that is permitted by the copyright and related rights legislation that applies to your use. For other uses you must obtain permission from the rights-holder(s) directly, unless additional rights are indicated by a Creative Commons license in the record and/ or on the work itself. This Thesis has been accepted for inclusion in WVU Graduate Theses, Dissertations, and Problem Reports collection by an authorized administrator of The Research Repository @ WVU. For more information, please contact researchrepository@mail.wvu.edu. 
Influences on Parents' Decision Making Prior to Youth Sport Program Enrollment

\author{
Karl E. Zang
}

Thesis submitted

to the College of Physical Activity and Sport Sciences

at West Virginia University

in partial fulfillment of the requirement for the degree of

Master of Science in

Athletic Coaching Education

\author{
Kristen Dieffenbach, Ph.D., Chair \\ Roch King, Ph.D. \\ Valerie Wayda, Ed.D. \\ Edward Etzel, Ed.D.
}

Department of Coaching and Teaching Studies

\author{
Morgantown, West Virginia
}

2015

Keywords: parent decision making, parent influences, parent motivations, youth sport

Copyright 2015 Karl Zang 


\begin{abstract}
Influences on Parents' Decision Making Prior to Youth Sport Program Enrollment Karl E. Zang
\end{abstract}

Current literature has previously reported on the potential benefits of sport participation (Dhurup, 2012; Tomik, Olex-Zarychta, \& Mynarski, 2012), which are also some of the main motivations parents enroll their children in youth sport programs (Kurnik, Kajtna, Bedenik, \& Kovac, 2013). Parents have also been reported as being both gatekeepers (Schwab, Wells, \& Arthur-Banning, 2010) and supporters (Holt, Tamminen, Black, Mandigo, \& Fox, 2009) in regards to their child's participation. This study surveyed 135 parents enrolled in participation youth sport programs in order to identify the influential factors on parents youth sport program selection. Assessed influential factors were compared to an established questionnaire on youth sport parents motivations for enrollment (Kurnik et al., 2013). It was observed that although motivations for program enrollment were similar to previous research (Hutchinson, Baldwin, \& Caldwell, 2003, 2008; Kurnik et al., 2013), other factors stood out. 'Child expressed interest' was most influential factor for program selection with 'close to home' and 'child has friends within this youth sport program' being second and third. This data suggest that parents may choose programs based on what they believe their child wants to do as opposed to health-related benefits reported in previous research. 


\section{Acknowledgements}

I would like to acknowledge my thesis committee for all of the help and guidance they provided me. Especially to my advisor, Dr. Kristen Dieffenbach, for the many hours she dedicated to my growth and development as a researcher and writer. I would also like to thank my parents and grandparents for always supporting me in any way they could. They also provided me with practical advice from their own academic experiences, backgrounds, and careers. Lastly, I would like to thank my little sister Kara. As she pursues her own advanced degree, we were able to bond over the process of becoming academic and research professionals. 


\section{Table of Contents}

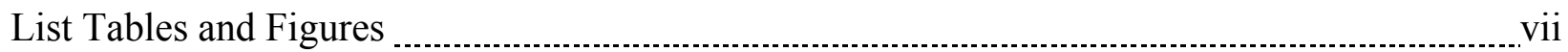

Introduction

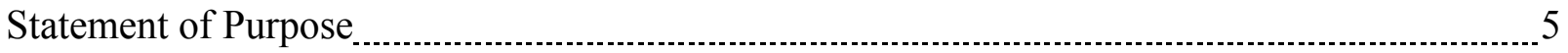

Review of Literature

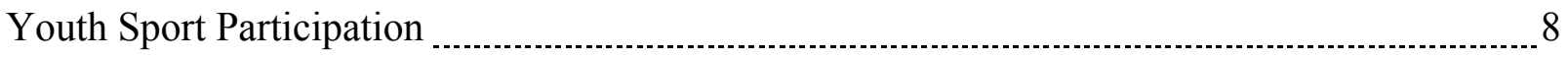

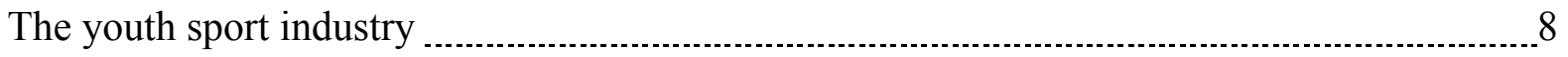

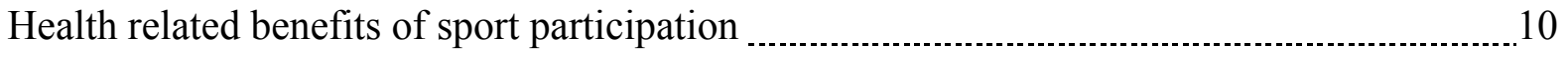

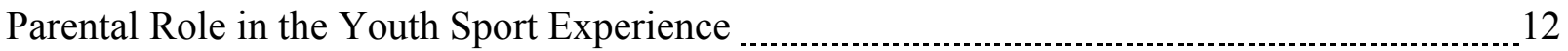

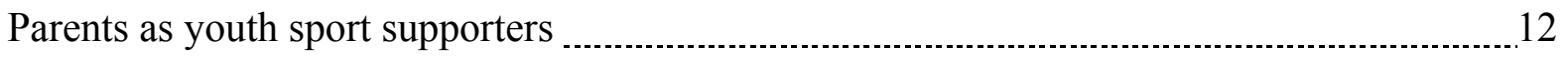

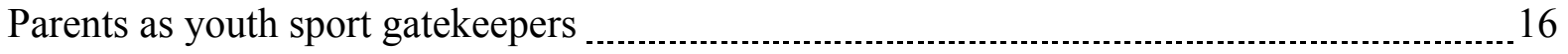

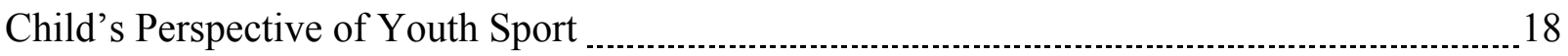

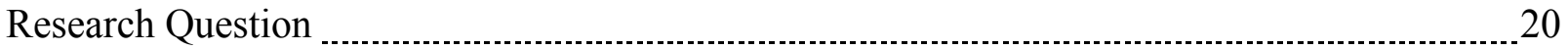

Method

Procedures

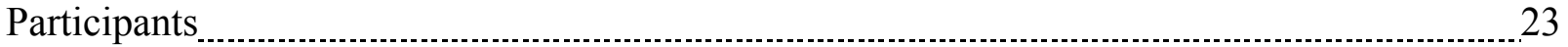

Instrumentation

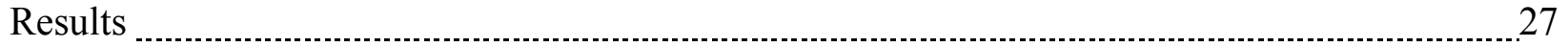

Parental Motivations for Youth Sport Program Enrollment _.............................................. 27

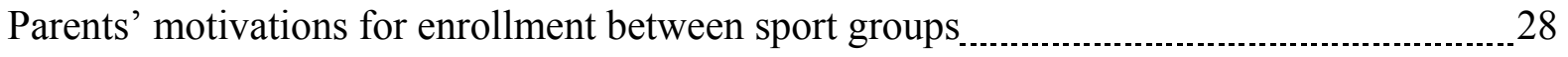

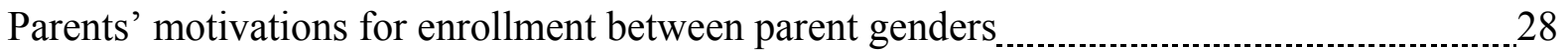

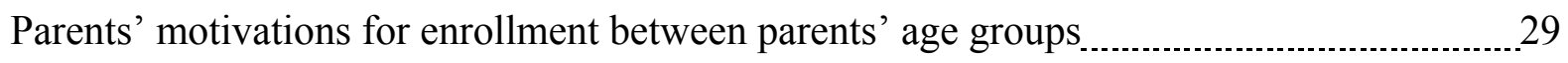

Parents' motivations for enrollment between parents' educational groups _......................... 29 
Parents' motivations for enrollment between children's genders

Parents' motivations for enrollment between children's age groups

Influential Factors on Parents for Youth Sport Program Selection

Discussion

Summary of Findings

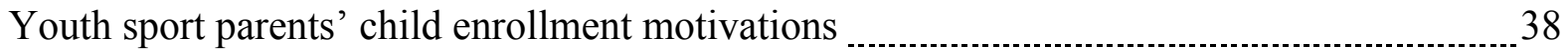

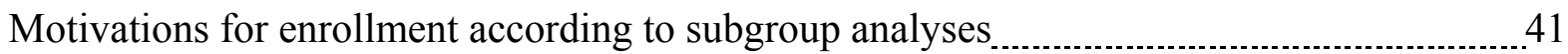

Influential factors on parental youth sport program selection $\ldots$

Relationship between motivational and influential factors $\ldots$

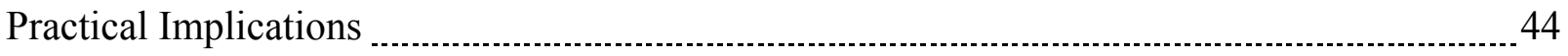

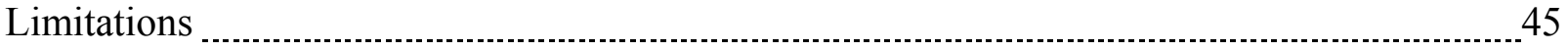

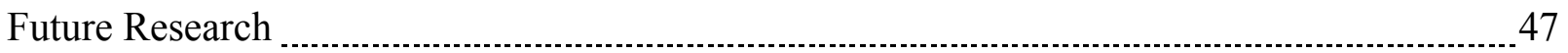

Conclusion $\ldots$

References

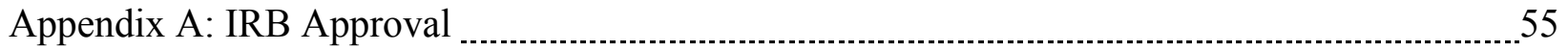

Appendix B: Introduction Email to Program Administrators …............................................. 57

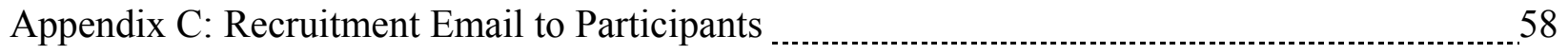

Appendix D

Appendix E: Influencing Factors on Parent's Decisions for Youth Sport Enrollment Survey _..... 60

Appendix F

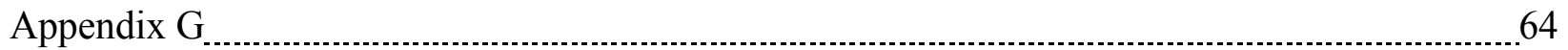

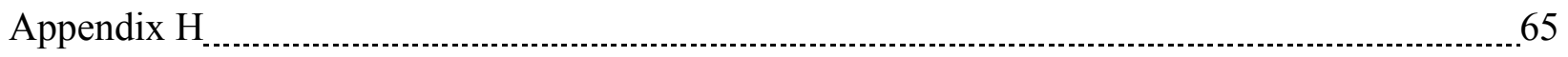

Appendix I 
Appendix J

Appendix K

Appendix L 


\section{List of Tables and Figures}

Demographic Information of Parents and Their Children 59

Overall Mean Ratings of Youth Sport Parents' Child Enrollment Motivations 63

Parental Motivations for Youth Sport Enrollment Differences between Parents' Genders 64

Parental Motivations for Youth Sport Enrollment Differences between Parents’ Age Groups _....65

Parental Motivations for Youth Sport Enrollment Differences between Parents' Educational Level Groups 66

Bonferroni Post-Hoc Test between Parents’ Educational Level Groups 67

Breakdown of 'Other' Influential Factors Responses into Higher- and Lower-Order Themes with Total Number of Responses 68

Top Responses Ranked as the Most Influential Factor for Youth Sport Program Selection 69 


\section{Introduction}

Wallerson (2014) reported the size of the youth sport industry across the United States at approximately 22 million participants in just four sports (e.g. football, baseball, basketball and soccer). The decision to enroll an athlete in youth sports is a complex one faced by millions of U.S. families. Parents have a dominant role in the decision for their children to participate in youth sport. Parental values, defined as their personal and/or societal beliefs about the benefits of sport participation during pre-adolescent development, have not been investigated to a great extent. To date, there is some literature exploring parental decisions to enroll their children in youth sport which focuses on motivations (i.e. expected outcomes) parents have (Kurnik, Kajtna, Bedenik, \& Kovac, 2013; Tomik, Olex-Zarychta, \& Mynarski, 2012), but little research exists on how they chose specific youth sport programs.

Youth sport is defined as any program that has participants under the age of 18 (National Association for Sport and Physical Education [NASPE], 2008; Pennsylvania State Association for Health, Physical Education, Recreation and Dance [PSAHPERD], 2008; Wallerson, 2014). The International Council for Coaching Excellence (ICCE) International Sport Coaching Framework (ISCF) distinguishes two types of sport programs. The first is performance sport, where "the development and demonstration of capabilities referenced against normative standards in competition are the main objectives (ICCE, 2013, pg. 53)." In comparison, participation sport, is any "sport in which the main priority is to achieve self-referenced outcomes such as personal improvement, healthy lifestyle, socialism, or enjoyment (ICCE, 2013, p. 53)."

It is a common assumption that youth sport participation is a valuable part of childhood. In the 2007- 2008 academic year, 50 million children under the age of 18 participated in youth 
sport (NASPE 2008; PSAHPERD, 2008). During 2008, there were roughly 24 million youth participants engaged in football, baseball, basketball and soccer, which dropped to just over 22 million during 2012 (Wallerson, 2014). Despite a decline in these specific sports, millions of children still participate in a wide range of youth sport. These children are potentially exposed to proper development of sport skills, an introduction to physical activity (Tomik et al., 2012), and positive motivational experiences (Schwab, Wells, \& Arthur-Banning, 2010). All of these benefits are assumed to affect future physical activity participation and other healthy lifestyle choices. The decision-making process of how parents are choosing to enroll and allow participation should be explored to help increase participation rates.

According to the Long-Term Athlete Development Model (LTAD), children aged 0 - 5 years old sport participation tends to emphasize foundational movement skills (e.g. agility, balance, coordination, and speed), rather than sport specific skills (Canadian Sport for Life, 2005). The next early stages of participation are considered "FUNdamental" and "Learn to Train" (Canadian Sport for Life, 2005). These two stages encompass the age range of $6-12$ years old and are crucial in developing physical literacy competence before and during the early stages of adolescence (Canadian Sport for Life, 2005). During adolescence, sport participation starts to become more specialized. The typical range of high school students who would participate in youth sport is approximately $13-17$ years old. Participation during this age range prepares sufficiently talented athletes for collegiate and high-performance sport competition. Therefore, the range of $6-12$ years old contains pre-adolescent athletes that have not yet started to specialize in sport but are starting to learn more than just foundational movements associated with sport and physical activity. Aside from focusing on parents with children enrolled in participation youth sport, those children were within the age range of 6 - 12 years old. 
The potential benefits of sport participation have also been investigated (Dhurup, 2012; Tomik et al., 2012; Schwab et al., 2010). Based on reported outcomes parents expect for their children (Dorsch, Smith, \& McDonough, 2009; Holt, Tamminen, Black, Mandigo, \& Fox, 2009; Schwab et al., 2010), parents assume that by merely participating in sport, their children will automatically gain certain benefits (e.g. discipline, teamwork, sport skill development). However, beyond these expected outcomes, there is little else known about the specific reasons why parents enroll their children in youth sport.

Current literature discusses the roles parents undertake as their children participate in youth sport (Dixon, Warner, \& Bruening, 2008; Dorsch et al., 2009; Holt et al., 2009; Kurnik et al., 2013; Schwab et al., 2010; Seifried, 2008). The two main roles parents assume during youth sport participation are gatekeepers (Schwab et al., 2010) and supporters (Holt et al., 2009). As gatekeepers, parents seem to view sport participation as a beneficial use of time (Hutchinson, Baldwin, \& Caldwell, 2003), with a wide variety of potential beneficial outcomes. Seifried (2008) reported that participation can help children learn self-discipline and teamwork. Other studies suggest that youth sport participation may help: create positive habits for maintaining health and well-being (Kurnik et al., 2013), build intrinsic motivation for physical activity (Holt et al., 2009; Tomik et al., 2012), and develop sport skills (Schwab et al., 2010).

Parents are also a main source of social support for their children. Being a supportive parent has beneficial effects on their children (Holt et al., 2009). This support can be expressed in a variety of ways including financial (Dixon et al., 2008), logistical, and game/practice attendance (Dorsch et al., 2009).

The parental dual roles of gatekeeper and supporter appear to have an impact on the level of physical activity to which their children are exposed and involved. The variety of and time 
spent participating in youth sport has potential impact on future physical activity levels (Dhurup, 2012; Dixon et al., 2008). It has been reported that individuals who participate in youth sport have more positive feelings about physical activity and physical fitness (Tomik et al., 2012). Therefore, it is likely that early athletic exposure will lead to future involvement.

Participation in youth sport does not automatically facilitate the development of positive character traits (e.g. self-discipline and teamwork) or healthy lifestyle habits (Blom, Bronk, Coakley, Lauer, \& Sawyer, 2013). The responsibility for facilitating positive benefits lies with the individuals who organize and run youth sport programs (Lumpkin, 2013), which typically includes coaches (Gearity, 2012) and volunteers (Barcelona \& Young, 2010). According to the National Coaching Report, during the 2007-2008 academic year, there were approximately 858,000 individuals who served as coaches in U.S. high school and youth sports. Of which approximately 750,000 were volunteers, with over 200,000 described as first-timers (NASPE, 2008). Many youth sport programs are largely run by volunteers across the country (Barcelona \& Young, 2010). Therefore, the development of healthy lifestyle and character traits is often left to individuals who may have no education or background on how to deliver an effective program (Forneris, Whitley \& Barker, 2013). Volunteers can pose an even larger problem depending on how, or if, youth sport programs screen and prepares their volunteers. For instance, if volunteers are not screened with background checks it could pose serious safety issues to the children whom participate (LaVetter \& Stahura, 2010).

Children's participation decisions rely on positive attitudes about physical activity that help build intrinsic motivation (Holt et al. 2009; Tomik et al., 2012). In other words, kids choose to initiate and perhaps stay involved because of enjoyment or fun of participation (Schwab et al., 2010). Parents of youth sport athletes may recognize the importance of intrinsic motivation 
during sport participation and have used this as a motive to keep their child enrolled in youth sport programs (Hutchinson et al., 2003). However, positive environments that develop intrinsic motivation are not inherent to youth sport culture (Gearity, 2012). Educated coaches provide a better chance of creating a positive environment that develops children's motivation for continued participation and positive character development (Smith, Smoll, \& Curtis, 1979; see also Barnett, Smoll, \& Smith, 1992; Smith, Smoll, \& Cumming, 2007; Smith \& Smoll, 1990). Besides seeking potential outcome benefits from participating, the decision-making process that parents utilize when enrolling their child in a youth sport programs is unknown. Within the current literature, there have been explorations about parental motivations to enroll their child (Kurnik et al., 2013) and on the perceived social values of physical activity (Tomik et al., 2012). The only relatable literature on parental decision-making processes found was related to the factors parents considered when making child care choices (Rose \& Elicker, 2008). Top influences on parents' child care decisions were caregiver's personality and education levels while cost and location were close behind (Rose \& Elicker, 2008).

While comparing the findings of parental decision making in child care (Rose \& Elicker, 2008) to the parental motivations for enrollment in youth sport (Kurnik et al., 2013; Tomik et al., 2012) the noticeable gap was identified on the absence of including availability or location of youth sport programs in relation to enrollment decisions. However, the cost of participation has been previously determined as a limiting factor for not participating in youth sport for families in lower socio-economic levels (Telama, Laakso, Nupponen, Rimpela, \& Pere, 2009).

\section{Statement of Purpose}

The purpose of this study was to explore the factors that influence parents' decisions on youth sport program selection and enrollment. Understanding this decision-making process may 
provide insight that can aid in the efforts in changing youth sport culture and providing beneficial sport related experiences for the youth of the United States. 


\section{Review of Literature}

The focus of this study was to explore parental decision making as it relates to the youth sport experiences they choose for their child. For the purposes of this project, youth sport program was defined as any sport program outside of scholastic based and/or school funded program for participants aged 6 - 12 years old where the emphasis is on participation. Participation sport, defined by the ISCF, is any "sport in which the main priority is to achieve self-referenced outcomes such as personal improvement, healthy lifestyle, socialism, or enjoyment (ICCE, 2013, p. 53). The child age range was selected based on the development literature that suggests that the $6-12$ year-old pre-pubescent age group is still reliant on parental support (e.g. financial, logistical, and emotional) and subject to parental influence regarding their youth sport experience (Schwab et al., 2010). Additionally, this age range has been labeled a foundational stage in the Long-Term Athlete Development Model (Canadian Sport for Life, 2005). This stage focuses on facilitating the child's preparation for the development of physical literacy, lifetime participation skills, and possible sport specialization (Kurnik et al., 2013; Lumpkin, 2008; Watson, Connole, \& Kadushin, 2013).

Within the sport context, parents play the role of both supporter and gatekeeper. The scope of this study focused on their role as a gatekeeper to youth sport participation. Little is known about the role of the parent as a gatekeeper to sport experiences or about the decisionmaking process parent's use for program selection. This study sought to contribute to youth sport literature and to provide key information to help improve the youth sport participation pathways.

In addition to the estimated 21 million youth sport participants (Aspen Institute, 2014) within the United States, there are millions of individuals coaching, volunteering, or administrating these youth programs. As a key part of the American landscape, youth sport 
participation has been ascribed a wide range of positive benefits. Such benefits include creating positive habits for maintaining health and well-being (Kurnik et al., 2013), building intrinsic motivation for physical activity (Holt et al., 2009; Tomik et al., 2012), and developing sport skills (Schwab et al., 2010). These benefits have developed into parental assumptions on expected outcomes for youth sport participation. Parents reported similar health related benefits as primary motivations for youth sport enrollment (Hutchinson et al., 2003; Kurnik et al., 2013). Additionally, there has been research dedicated to the child's perspective of continued participation (Barnett et al., 1992; Smith et al., 2007; Smith et al., 1979; Smith \& Smoll, 1990), and how coaches can have a negative effect on player experience (Gearity, 2012). Together, this information has provided a clear picture of what is known about the youth sport participation expectations and experiences that can influence parents, and their children, towards youth sport enrollment.

\section{Youth Sport Participation}

Youth sport is a large and influential industry within the United States. It has a longstanding history of providing youth with competition and the development of sport skills; other health related benefits have started to become apparent as well. This section will explore the size and scope of the American youth sport industry, the roles and responsibilities of adults within youth sport, and the potential benefits of participation.

The youth sport industry. The youth sport industry has been an integral part of the American youth experience since the early 1900s. With Pop Warner Football being founded in 1929 (“Pop Warner”, 2015) and Little League baseball in 1939 ("Little League”, 2015), these two national youth sport programs have had generations of young participants. Despite its cultural significance, Wallerson (2014) reported youth sport participation rates have declined 
from 2008 - 2012. Wallerson compiled data from the National Federation of State High School Associations (NFHS), the U.S. Census, the Sports and Fitness Industry Association (SIFA), the Physical Activity Council and the U. S. Soccer Federation, and reported that the number of youth participants engaged in youth football, baseball, basketball and soccer was roughly 24 million individuals in 2008, dropping to just over 22 million during 2012. It should be noted that during the same period $(2008-2012)$ ice hockey participation increased from 330,000 to 550,000 (64.0\% increase) and lacrosse participation increased from 300,000 to 770,000 (158.1\% increase) (Wallerson, 2014). The raw numbers of those participating in youth sports show the impact sport has on this country. With that in mind, understanding the parental decision-making process for youth sport participation should be explored. Without fully understanding why participation numbers are dropping, one underlying assumption might be that parents are not putting their children in sport. The 'why' can be better explained if it can be found out how parents make their decisions.

In 2008 the National Association for Sport and Physical Education (NASPE), released the National Coaching Report (NCR) that provided "a snapshot of what interscholastic and youth sport organizations [were] currently requiring of coaches [at those levels]" (p. 7). The NCR reported the number of athletes in both interscholastic and youth sport levels as 14 million, with approximately 7.5 million interscholastic athletes and 6.5 million youth athletes (NASPE, 2008). At the youth sport level, only ten of twelve surveyed programs provided coaching data for the National Coaching Report (NASPE, 2008). The number of coaches associated with those ten programs was just over 618,000 . Five of those programs reported a total of approximately 229,000 first time coaches within their coaching population (NASPE, 2008). This report only scratches the surface of the many people involved with youth sport across the country. The NCR 
suggests that there are almost as many adults as young athletes who either coach directly or are program administrators that influence the levels of coaching these athletes receive yearly. It is these adults who run the youth sport programs that will benefit most from understanding the parental decision-making process. Deciphering what influences parents' program selection and enrollment decisions can help program administrators to guide their programs into a direction that can draw parents and youth athletes in for participation.

Health related benefits of sport participation. According to the U.S. Census Bureau (2015), there were approximately 50 million children between the ages of 6 and 17 in 2014 and approximately 21 million youth sport participants (Aspen Institute, 2014). Approximately 42\% of the nation's youth were involved with youth sport. Despite this percentage of youth sport participants, there is still a health crisis in the United States. According to the Centers for Disease Control and Prevention (CDC), the percentage of American youth classified as obese has held steady at 17\% since 2004 (Ogden, Carroll, Kit, \& Flegal, 2014). While their overall conclusion was that no significant changes in obesity prevalence had occurred, when they did subgroup analysis on children aged 2-5, there was a 6\% drop in obesity levels from 2003-2004 to 20112012 (Ogden et al., 2014). The following section of research suggests that if more of the nation's youth are active in sport, obesity rates could start to drop.

Participating in physical activity on a regular basis has the potential to improve muscle strength, metabolism, academic performance, and decrease stress and anxiety (Dhurup, 2012). Two-hundred and eighty university students who were engaged in physical activity were surveyed and asked to rate the degree of applicable perceived benefits as they related to their participation in physical activity (Dhurup, 2012). Extracted from the data were four factors, health promotion benefits, revitalization, physical appearance and self-esteem, and stress 
management (Dhurup, 2012). Health promotion, which accounted for $43 \%$ of the variance, was the most prominent factor. While revitalization accounted for $10.55 \%$, the last two factors of physical appearance and self-esteem (5.7\%), and stress management (4.85\%) were fairly close (Dhurup, 2012). This particular study shows that students who engage in physical activities were aware of the potential benefits and were the main reasons for such participation. Since these adults were aware of the potential benefits of being physically active, it could be suggested that they also assume similar benefits for their children. These perceptions can dictate parents' decision-making processes for initiating sport participation for their children.

The SHAPE America position statement (Blom et al., 2013) concerning youth sport participation states, "Young people who play sports are likely to experience physical, psychological, academic, and social benefits" (p. 8). Blom and colleagues (2013) specify each potential benefit category in more descriptive detail throughout the paper. In regards to health and physical benefits, research reports that multi-sport participation can maximize and enhance opportunities for skill and physical development (Beets \& Pitetti, 2005). However, research also states that for these potential benefits to occur, especially those related to health and psychological growth, youth participation is enhanced by a safe environment, includes positive social norms, and has an emphasis on self- and physical improvement (Light, 2010; Tomik et al., 2012). The SHAPE America statement (Blom et al., 2013) recognizes that those benefits have a higher likelihood of occurring in an environment fostered by the encouragement of skill development, participation, and respect. Coaches need to have the knowledge that can cultivate the positive experiences that lead to continued physical activity. Having this skill set can also help show parents their child is receiving the expected benefits of youth sport participation, thus 
increasing the likelihood of future participation and/or advocating that program for first-time youth participants.

\section{Parental Role in the Youth Sport Experience}

Parents are consumers of youth sport programs since they are the final decision makers of youth participation (Schwab et al., 2010). Research has indicated that parents of youth sport athletes adopt two main roles, supporters (Holt et al., 2009) and gatekeepers (Schwab et al., 2010). As supporters, parents provide financial costs of participation (e.g., league/program fees, equipment costs, food, etc.) (Dixon et al., 2008), transportation logistics, organization/program volunteers (Dorsch et al., 2009), and emotional support (Nunomura \& Oliveira, 2013). As gatekeepers, they provide the opportunities for participation in specific sports and programs (Hutchinson et al., 2003). Ultimately, it is the parents' decision to allow their children to participate in youth sport programs. As such, determining how parents' make those enrollment decisions' could potentially help youth sport programs attract and retain participants.

Parents as youth sport supporters. Parental interactions with their children have a direct effect on the child's engagement and enjoyment on athletic participation. Once young athletes are involved in athletic participation, research has found that parental support can be perceived in different ways. Holt and colleagues (2009) state that "supportive parenting is more beneficial for enhancing children's and adolescents' well-being and intrinsic motivation than controlling parenting” (p. 55). While researching parenting styles in youth sports, Holt and colleagues (2009) found distinct styles parents' implemented to show support for their children throughout a season. Thirty-two couples who had 87 children between them were observed and interviewed for the data collection. The emergent parenting styles were autonomy-supportive, controlling, and a mixture of these two (Holt et al., 2009). The authors expressed concern in 
discussing their results when "a mother and a father reporting different styles" (Holt et al., 2009, p. 55). This is of note as the decision-making process related to entry into sport participation may be a product of multiple influences between the child and parents, or it could be a function of one parent simply making the decision solo.

Youth sport participation has been linked to extrinsic motivators, such as parental influence (Kanters, Bocarro, \& Casper, 2008). Parental influence is not automatically positive or negative, and can be perceived as either adequate support and encouragement or a high degree of pressure on their child (Kanters et al., 2008). Kanters and colleagues (2008) surveyed youth hockey players aged $9-11$ years old and their parents across twelve travel teams in the southeastern United States. One-hundred eight kids and their parents completed a web-based survey that allowed families to be submitted together using a unique password to each family group. Child perceived pressure from fathers negatively correlated with general feelings about hockey, but parent perceptions were not significantly different and were combined as one for variable analysis (Kanters et al., 2008). Kanters and colleagues (2008) reported that "parents and their children do not agree on measures of parental pressure and support in their children's sport" (p. 74). This difference mainly dealt with parental attitudes and communication tools when discussing sport with their children. While initial youth sport participation may be more in the hands of the parent, continued participation has been linked to the child's perception of enjoyment and the overall perceived positive influences they receive from their parents.

Nunomura and Oliveira (2013) reported "that most children perceive their parents as major motivators [for athletic success]" (p. 9). One hundred and sixty-three youth gymnasts, aged $9-18$, across twenty-nine sport institutions, were surveyed on their perceptions of their parents' behaviors and attitudes while participating in a sport program (Nunomura \& Oliveira, 
2013). The player perceptions indicated that younger athletes, ages $9-12$, relied on their parents more for emotional support during times of discouragement, but sometimes even this support led to perceived pressure if presented wrong. While parents may see themselves as supporting and encouraging their children's athletic endeavors, “depending on the degree and form of this involvement this can be perceived by the child in a negative way" (Nunomura \& Oliveira, 2013, p. 14). Most of the disparities between support and pressure perceptions had to do with improper parental communication strategies, such as keeping their child participating for their health but emphasizing winning and competitions (Nunomura \& Oliveira, 2013). This disparity of support and pressure could be an indication of expecting certain outcomes but choosing programs that don't reflect or provide those expectations.

Parental encouragement of youth sport participation can be provided in a variety of ways. Dixon et al. (2008) examined the parental influence on lifetime sport involvement of seventeen female Division I head coaches. These head coaches reported that their parents supported their youth sport involvement in three ways: role modeling, providing experience, and interpreting experience (Dixon et al., 2008). Parents were reported to be providers of experience mainly through game attendance (Dixon et al., 2008). This type of support was reported by all participants and "one that participants specifically recalled and most frequently mentioned (Dixon et al., 2008, p. 549)." Other ways of active support reported were helping out with coaching/administration, volunteering their time, and transportation for games/practices (Dixon et al., 2008). This research shows that parental influence can have long-lasting, lifetime influences. As supporters, parents can influence sport participation or being physically active in general. The participants for Dixon and colleagues (2008) study all came from athletic families, which seemed to value sport as part of childhood experiences. Valuing sport as a fundamental 
childhood experience could have been a determining factor for initial sport participation. One participant mentioned that "sports were just immediately a part of [their] lives (Dixon et al., 2008, p. 548)." In this instance, the values placed on youth sport participation were enrolled into familial values. Which could have had resulted in different decisional influences for initial youth sport participation, but specific values were in mind during that decision making process. The question remains, what were those influential factors/values that initially opened youth sport experiences up for these Division I head coaches.

Aside from investing time and energy parents put into supporting their child in sport, the financial support of sport pursuits has also been addressed as an important contribution to youth sport research. "The financial responsibilities of being a youth sport parent were also salient. Some parents labeled this support as a sacrifice, whereas others described this financial support as an investment" (Dorsch et al., 2009, p. 454). Twenty-six youth sport parents, with a total of seventy-four children (average age of 14), participated in focus groups about their socialization in terms of their children's sport participation (Dorsch et al., 2009). Parents noted differences in expectations regarding financial and time burdens but overall described these supporting factors as drives "to provide their children with the best possible youth sport experience they could" (Dorsch et al., 2009, p. 454). It is with this mindset that parents adopted a supportive role within their child's youth sport participation. More supportive parents may also have specific values they hold onto before placing their child in sport. Those values could differ between parents who also differentiate between investment/sacrifice for sport involvement. If parents want the best experience possible youth sport experience for their child, then it might be expected that their decisional influences would reflect this belief. 
Parents as youth sport gatekeepers. Participation in entry level youth sports is predicated on community, socio-economic, and opportunity factors (Dorsch et al., 2009; Telama et al., 2009). In suburban communities, for school-aged children, parents hold the decisionmaking power in regarding the extra-curricular activity participation of their children (Holt et al., 2009; Schwab et al., 2010). For many young athletes, parents hold the key to participation as they are ones providing the transportation and monetary contributions necessary for these activities (Telama et al., 2009). As such suburban parents can be seen as the gatekeepers to young athletes' entry and participation in sport programs.

The limited research in this area has found that parents enroll their children in youth sport programs because of the perceived potential benefits of youth sport participation and that they see youth sport as a beneficial use of their children's "free time (e.g., when not in school)," (Hutchinson et al., 2003, p. 397). Hutchinson and colleagues (2003) surveyed parents recalling how their child (12-14 years old) spent their free time within previous time parameters (e.g. yesterday, last week, last month). Parents reported sport activities and music as beneficial uses of free time, as opposed to watching TV or playing video games (Hutchinson et al., 2003). Certain activities were required by parents during leisure time, such a swimming because the parents valued it as a survival skill (Hutchinson et al., 2003). Since parents' have the final decision on their child's participation within suburban communities, their attitudes on what their children engage in are significant. This study suggests parents' decision process for youth athletic participation could be influenced by what they deem appropriate uses of time outside of school.

One study in particular came very close to filling in the literature gap that sparked this study. Kurnik et al. (2013), asked 386 parents of young gymnasts, 7 - 9 year-olds, to rank their motivations for enrolling their children in gymnastics According to Kurnik and colleagues, 
parents listed health and well-being as their top motivations to put their child in a sport program. This study also reported that there were some differences in parental motivation based on their age, such as younger parents listing competition of greater importance. Kurnik and colleagues (2013) make note that there were no statistical differences between mothers and fathers on reported enrollment motivation. These results are consistent with parents wanting their children to receive health-related benefits of sport participation (Hutchinson et al., 2003). While parents want and expect their child to receive health-related benefits during sport participation, these are not direct results automatically achieved while participating in sport.

Continual youth sport participation can generate healthier attitudes about being physically active. It can also reinforce the same healthy habits learned in previous years. Tomik and colleagues (2012) suggest sport participation factors into facilitating more positive perceptions of physical activity stating "members of school sports clubs display more pro-social attitude towards sport and physical education than their peers uninvolved in the sport process" (p. 104). It is clear that the predominant factors for parents to engage their children in youth sport participation are the promotion of learning healthy lifestyle habits and engaging in physical activity. By consistently reporting health benefits as a major factor for youth sport participation, the parental decision process can start being studied in terms of selecting youth sport programs that reflect those same values and expectations.

However, there are unexplored influential variables for sport program selection. Parental decision-making processes have been explored within child care literature (Rose \& Elicker, 2008). Rose and Elicker (2008) surveyed 355 mothers about their child care selection process and determined that warmth and education level of the caregiver were rated as most important. A play based curriculum was also rated high, with cost and location close to home closing the top 
five influential variables (Rose \& Elicker, 2008). In order to draw a parallel from this study, coaches could be seen as the caregiver and participation in youth sport is primarily play based. The other two variables, cost and location, could very well be influencing decisional factors for youth sport participation too. However, since there is currently no literature exploring the initial enrollment decision parents make, the only thing to know for sure is that they expect their child to get some benefit from participating in youth sport.

\section{Child's Perspective of Youth Sport}

Even with parents making the final decision for participation in youth sports (Hutchinson et al., 2003; Schwab et al., 2010), children are still going to have separate experiences than their parents (McCullagh, Matzkanin, Shaw \& Maldonado, 1993). If children's perspectives of youth sport are influential factors for parental decision making of enrollment, then those views should be addressed as well.

A study conducted by McCullagh et al. (1993) reported the differences parents and children have on motivations for youth sport participation. The top three motivations for both groups were intrinsic in nature (e.g. to have fun, have a good time, feel good during play), while the lowest were extrinsic (e.g. to win, trophies/ribbons, equipment), and the remaining twenty motivations did not match between parents and children (McCullagh et al., 1993). In this instance, parental motivations were affected by child's perspectives of youth sport participation. Which indicates that further investigation into parental decision making is needed to understand why parents choose specific programs.

Participation in physical activity from a child's perspective is based, in part, on having a positive attitude towards physical activity (Tomik et al., 2012). Tomik and colleagues (2012) selected 623 school-based sport clubs across Poland and received a total of 2,704 survey 
responses. Overall, boys reported more positive attitudes of physical education and sport participation than girls (Tomik et al., 2012). However, individuals involved with sport clubs outside of a physical educational context reported more positive attitudes about physical activity regardless of gender; and girl sport participants had the largest positive differences in attitude towards sport versus their noninvolved peers (Tomik et al., 2012). This study suggests that sport involvement outside of physical education has a bigger impact on attitudes towards physical activity in general. These positive attitudes can turn into positive motivation for continual participation of physical activity later in life. Children who have positive perceptions of being physically active may influence their parents to enroll them in youth sport programs.

Research conducted by Schwab and colleagues suggests that "young athletes may transfer or cease their participation in youth sports if any of their expectations for participation are not met" (2010, p. 43). Schwab and colleagues (2010) surveyed 143 parents and 224 players from a Midwest youth football program. The players ranged from ages $6-14$ (with an average age of 11). Parents' were also surveyed for parental perceptions relating to sport participation. Players reported 'Fun in the League' as the highest mean rated ('could not be better'), component of the program followed by 'Overall Experience' and 'Teamwork Development', with 'League Sportsmanship' rated lowest ('needs improvement') (Schwab et al., 2010).

Perception differences between parents and players were statistically significant in all categories but one ('League Sportsmanship'), with the most significant differences being 'Skill Development', 'Teamwork Development', and 'Overall Experience' (Schwab et al., 2010). The experiences between the two primary consumers of sport participation are very different, and programs need to ensure both parties are happy if they wish to grow. 
Schwab and colleagues (2010) note the differences in perceptions of youth sport participation stating, "these results could also mean that young athletes may simply be looking for different experiences or may hold differing expectations than their parents" (p. 47), and that, "professionals must clearly understand that starkly different perspectives and sets of expectations regarding youth sport experiences may exist between the two groups" (p. 47). The transferability of this study is limited because it was only one football program and all players were male. A similar study within the same age bracket may differ depending on sport program, competitive or seriousness level of the program, and included genders. This study provides a baseline of perceptional differences between parents and their child athletes in regards to participation and the decisions of why they continue to engage in sport based physical activity. However, the initial participation of youth sports may have different influences on children and parents.

\section{Research Question}

Youth sport programs in the United States have the potential to provide a fundamental framework for lifetime sport and physical activity participation for millions of children. Parents expect and assume positive life skill and experience benefits that they associate with youth sport participation. To date, the research on parental involvement in their children's sport experience has centered on expected outcomes of physical activity as it relates to health (Hutchinson et al., 2003; Kurnik et al., 2013), skill development, and enjoyment (McCullagh et al., 1993).

Currently, no research has been conducted that explores the factors that influence how parents make decisions about which youth sport programs to enroll their child.

Based on the identified gap in the existing literature, this study was focused on the following research questions in order explore what influences parents during their decisionmaking process regarding their child's sport experience. 
First, what motivates parents to enroll their children in youth sport? Current literature suggests that these motivations are centered around physical activity and with the associated assumed benefits (Holt et al., 2009; Hutchinson et al., 2003; Kurnik et al., 2013;Tomik et al., 2012; Schwab et al., 2010). Literature also suggests that these motivations may change based parental age, gender, and education level (Kurnik et al., 2013; Tomik et al., 2012). Based on the existing literature, it is expected that parental motivations will be centered on physical activity and the associated potential benefits. It is also expected that the motivations will be different based on parental age, gender, and educational level.

Second, what influences parents while selecting a youth sport program to enroll their child? It is expected that some of these influences are also centered on the same attributes that parent's use as motivations for enrollment. It is also expected that other reported influences are a part of an unexplored area such as cost or location of programs.

Lastly, is there a relationship between parents' motivations for youth sport enrollment and the influences on their program selection decisions? Parents may want their child to be active and develop sport skills, but they choose a program because it is cheap and close to school. Parents could also be choosing programs solely based on the type of sport. Since parents have reported wanting their child's youth sport experience to be the best possible (Dorsch et al., 2009), there should be a relationship present. 


\section{Method}

\section{Procedures}

Potential parent participants were identified through their child's participation in youth sports programs that were selected based on the ICCE's definition of youth participation sport (2013). Youth sport program selection criteria for inclusion in the study were: a) all children who join the program were allowed to participate, b) program registration fee was less than 100.00 USD per participant, and c) fitness and foundational sport skill development was emphasized over competition within the program's mission statement and/or related program materials. Further, selected programs did not: d) cut players at any point due to athletic ability, or e) require post-season/tournament play. If post-season/tournament play was offered, it had to have been optional, allowing each child/family to choose to participate. Selected programs met all of the inclusion criteria and did not possess any of the exclusion criteria.

Within the identified community, a youth baseball program and a youth soccer program were selected based on the stated criteria. The baseball program served approximately 1,350 families while the soccer program served approximately 730. After IRB approval had been obtained (see Appendix A), the two selected youth sport programs were contacted to gain their approval and permission to contact parents. A cover letter was emailed to youth sport program administrators explaining the research study and requesting permission and assistance in sharing the study information with their youth sport parents (see Appendix B). When available, youth sport parent email addresses were requested for online recruitment. For the youth sport programs that did not have or were not willing to share parental email addresses, program administrators distributed a copy of the introductory email (see Appendix C). The introductory email introduced the researcher to the parents, explained the purpose of the study and contained a 
link to the online survey. For each program, only one email was sent via the researcher or the program administrators, i.e. each potential participant only received one invitational email.

\section{Participants}

Purposeful sampling was used to select youth sport parents for participation in this study. A mid-Atlantic, mid-sized suburban community was the target population from which the survey sample was taken. Target participants were parents with a young athlete, between the ages of 6 and 12 years old, who was enrolled in a youth sport program that had been pre-screened by the researcher based on youth sport program inclusion criteria.

There were approximately 2,000 potential participants were invited through email to take the online survey. There were 162 returned surveys, approximately $6.6 \%$ return rate. There were 10 responses that were eliminated based on incomplete surveys. An additional 17 responses were eliminated based on child's age being outside of the range $6-12$ years old. A total of 135 survey responses were used.

Parents ranged in age from 26 to 62 years old $(M=40.28, S D=6.80)$ and the mean age of children was $9(S D=2.02)$. Of the parents who responded, 88 were female $(65.2 \%)$, and 47 were male (34.8\%). The respondents reported having 107 male children (79.9\%), 27 female children (20.1\%), and 1 did not specify. Two youth sport programs, baseball $(n=75,55.6 \%)$ and soccer $(n=57,42.2 \%)$, were reported by the majority of the participants while a small percentage $(n=3,2.2 \%)$ did not specify their sport program enrollment. Most frequent parental education level reported was bachelor's degree (31.1\%), followed by master's degree (25.2\%), Ph.D./M.D./J.D./similar degree (23.7\%), high school/GED (12.6\%), and associate's degree (7.4\%) (see Appendix D). 


\section{Instrumentation}

This study was of pre-experimental design as a descriptive study (Campbell \& Stanley, 1963; Huck, Cormer, \& Bounds, 1974) and was exploratory in nature. The survey was webbased and hosted online using Qualtrics ${ }^{\circledR}$. Participants were asked to complete a mixed methods survey consisting of three sections. Before the whole survey could be accessed, participants were asked to choose which pre-screened program they were associated with and the corresponding sport within that program. This allowed for the survey to automatically customize the questions to help ensure the participants' focus remained on the sport program enrollment of their child. For example, instead of a generic statement "My child has friends enrolled in this youth sport organization", the question read "My child has friends enrolled in [this soccer/baseball organization]”. According to the Qualtrics ${ }^{\circledR}$ timing software and piloting the survey for time, approximately five to ten minutes was needed to complete the online survey (see Appendix E).

The first section of the survey gathered demographic information about the parent or guardian taking the survey and their child, aged $6-12$, who was enrolled in this particular youth sport program. If the parent had more than one child who met these criteria, parents were instructed to complete the survey with their oldest child in mind. The percentage of participants who fell into this category is unknown. However, to anticipate this possibility, it was added to ensure the responses were about one child. Parental demographic data collected were age, gender, and education level. Survey participants were also asked to provide demographic information regarding their child about age, gender, and any additional sport activities in which their child has participated.

The second section of the survey consisted of a questionnaire that explored parents' motivational factors for enrolling their child in their respective youth sport program. This 
questionnaire had 30 items for youth sport parents' child enrollment motivations that were modified from Kurnik et al.’s (2013) original survey, which was specific to gymnastics. Modifications were made to make the survey applicable across all sports by replacing 'gymnastics' with the specific sport selected at the beginning of the survey. The modification was done only to the last five items since they were originally worded for gymnastics. For example, "Gymnastics will develop his/her abilities", the question read "Soccer [or baseball] will develop his/her abilities". Participants were asked to rate each of the 30 motivational items on a 5-point Likert scale, where ' 1 ' represented a 'not at all important' motive and a '5' represented a 'very important motive' for program enrollment. A further modification to the original survey was changing the anchor for ' 1 ' from 'unimportant' to 'not at all important' to ensure clarity of the lowest possible rating (see Appendix E).

The third and final section of the survey consisted of a questionnaire that explored influential factors on parents prior to the youth sport program selection for their children. This questionnaire provided parents with a list of 10 possible influences for youth sport program selection that was developed from Rose and Elicker's (2008) findings on the decision-making process of parents regarding child-care selection. Five of these items were automatically reworded based on the participants chosen youth sport program from the beginning of the survey. For example, instead of "within this youth sport organization," items read "within this [chosen soccer/baseball organization]" (see Appendix E).

After completing the 10 item survey, participants were also given the opportunity to write-in any influential factors if they felt played a role in their decision making process regarding their child's youth sport involvement but that were not present on the list. Using the provided list, and/or any influential factors they listed, participants were asked to rank their top 
five factors that they felt most influenced their decision in selecting that specific youth sport program for their child. Participants were told to use a rank of ' 1 ' for 'the most important reason' and then rank additional reasons ' $2-5$ ' according to importance (see Appendix E). 


\section{Results}

\section{Parental Motivations for Youth Sport Program Enrollment}

Response data from the modified youth sport parents' child enrollment questionnaire were analyzed using the Statistical Package for the Social Sciences (SPSS), version 21.0. One hundred thirty-five participants completed the survey. The range and mean score was determined for each item and the 30 items were ranked from highest to lowest scores for reported parental motivation for youth sport program enrollment decisions. The three overall highest ranked motivations were, 'my child will have fun at sport' $(M=4.72, S D=0.51)$, 'my child enjoys sport' $(M=4.59, S D=0.73)$, and 'my child likes to play' $(M=4.58, S D=0.67)$. The three overall lowest ranked motivations were, 'my child will look better' $(M=1.99, S D=1.06)$, 'because I used to play [soccer/baseball]' $(M=1.79, S D=1.25)$, and 'It will give me more free time' $(M=1.25, S D=0.67)($ see Appendix F $)$.

For this study, one-way analyses of variance (ANOVA) were the chosen for analysis based on the hypothesis that the rankings from the survey were dependent on specific independent variables within the demographic data (e.g. sport enrollment, parent age, parent gender). ANOVAs are used to determine if there are statistical significant differences between multiple groups of means. Similar to a two sample $t$-test, a one-way ANOVA does produce the same mathematical results when comparing two group means, but is more versatile since it is also able to compare three or more means at the same time if need be (Huck et al., 1974). Since certain independent variable subgroup comparisons were expected to have more than two subgroups analyzed (e.g. parents age, parents education level), one-way ANOVAs were chosen for all comparisons regardless of subgroup numbers. 
To reduce the level of Type-I error from a one-way ANOVA, $p$-value significance was $p$ $\leq .05$. This ensured that a 2 -tailed analysis accurately reported a statistical significance as the hypotheses are not directional (i.e. mothers and fathers ranked dependent variables different but no prediction of which group ranked which dependent variables higher/lower). The items on the survey responses were used as dependent variables in one-way ANOVAs. Participant demographic data were used as independent variables for one-way ANOVAs.

Parents' motivations for enrollment between sport groups. A one-way ANOVA was run between respondent groups of those with children enrolled in baseball $(n=75)$ and in soccer $(n=57)$. The hypothesis for this analysis was that parents' motivations for enrollment may be dependent on choice of sport. However, no statistically significant differences were found.

Parents' motivations for enrollment between parent genders. A one-way ANOVA was run between respondent groups of male $(n=47)$ and female $(n=88)$ parents to examine differences in their motivations to enroll their children in youth sport. The hypothesis for this analysis was that parents' motivations for enrollment may be dependent on parent's gender. A one-way ANOVA demonstrated four motivational factors for enrollment with statistically significant differences between parent gender groups. 'My child will acquire competitive experience' $(F[1,133]=7.99, M S E=1.41, p=.005)$, was reported higher among fathers $(M=$ $3.79, S D=1.06)$ than mothers $(M=3.18, S D=1.25)$. 'Because I used to play [soccer/baseball]' $(F[1,133]=6.37, M S E=1.50, p=.013)$, was reported higher among fathers $(M=2.15, S D=$ 1.37) than mothers $(M=1.59, S D=1.14)$. 'I would like my child to learn new skills' $(F[1,133]$ $=7.44, M S E=0.79, p=.007)$, was reported higher among mothers $(M=4.38, S D=0.79)$ than fathers $(M=3.94, S D=1.05)$. '[Soccer/baseball] will develop his/her abilities' $(F[1,132]=$ 
$11.78, M S E=0.86, p<.001)$, was reported higher among mothers $(M=4.17, S D=0.84)$ than fathers $(M=3.60, S D=1.08)$ (see Appendix G).

Parents' motivations for enrollment between parents' age groups. Kurnik et al. (2013) used the reported mean age of the parents during their one-way ANOVA between parents' age groups. The mean reported parents' age for this study was $40.28(S D=6.80)$. To ensure adequate sample size for analysis, respondents were separated into two age based groups, those reported being 39 years old or younger $(n=69)$ and those who reported being 40 or order $(n=63)$. A one-way ANOVA was run between respondent groups using parents' age groupings. The hypothesis for this analysis was that parents' motivations for enrollment may be dependent parents' age group. Only 'by participating in [soccer/baseball], he/she will acquire basic motor skill, important for all sports' $(F[1,130]=5.19, M S E=1.15, p=.024)$ was found to have statistical significant difference between parents' age groups. Parents aged 39 years old or younger rated this motivational factor higher $(M=4.19, S D=1.06)$ than parents aged 40 years old or older $(M=3.76, S D=1.09)$ (see Appendix H).

\section{Parents' motivations for enrollment between parents' educational groups.}

Educational level demographic data was used to place respondents into one of three groups based on their reported level of education. These groups represented parents with an advanced and professional degree $(n=66)$, those with an earned Bachelor's degree $(n=27)$, and those with at least a high school education and/or some college $(n=42)$. A one-way ANOVA was run between respondent groups according to parents' educational level group. The hypothesis for this analysis was that parents' motivations for enrollment may be dependent on the level of education parents had received. A one-way ANOVA between these three groups demonstrated five motivational factors for enrollment with statistically significant differences (see Appendix I). To 
examine where the significance ( $p \leq .05$, two-tailed analysis) between parental education level groups occurred for these motivational items, Bonferroni post-hoc tests were conducted (see Appendix J).

Only 'By participating in [soccer/baseball], he/she will acquire basic motor skill, important for all sports' $(F[2,132]=4.678, M S E=1.11, p=.011)$ was shown to have a statistical significant difference from a one-way ANOVA but not from the Bonferroni post-hoc test. This motivation was rated highest by those with high school and/or some college $(M=4.33$, $S D=.877)$, followed by those with a bachelor's degree $(M=4.21, S D=.842)$ and those with an advanced/professional degree $(M=3.71, S D=1.22)$. According to the post-hoc test, the difference between those with high school and/or some college compared to those with a bachelor's degree was not statistically significant. While the difference between those with a bachelor's degree compared to those with an advanced/professional degree approached a statistically significant threshold, but did not reach it. A similar trend was found when comparing those with high school and/or some college to those with an advanced/professional degree in which a difference approached a statistically significant threshold, but did not reach it.

'[Soccer/baseball] will develop his/her abilities' $(F[2,131]=4.95, M S E=.879, p=.009)$ was reported highest by those with high school and/or some college $(M=4.22, S D=.751)$, followed by those with a bachelor's degree $(M=4.21, S D=.750)$ and those with an advanced/professional degree $(M=3.71, S D=1.10)$. According to the post-hoc test, the difference between those with high school and/or some college compared to those with a bachelor's degree was not statistically significant. The difference between those with a bachelor's degree compared to those with an advanced/professional degree was found to be statistically significant. The difference of those with high school and/or some college compared 
to those with an advanced/professional degree did not reach the threshold of a statistical significance.

'I would like my child to learn new skills' $(F[2,132]=5.53, M S E=.778, p=.005)$ was rated highest by those with high school and/or some college $(M=4.56, S D=.641)$, followed by those with a bachelor's degree $(M=4.40, S D=.767)$ and then by those with an advanced/professional degree $(M=3.97, S D=1.02)$. According to the post-hoc test, the differences between those with high school and/or some college compared to those with a bachelor's degree and between those with a bachelor's degree compared to those with an advanced/professional degree was found to not be statistically significant. However, the comparison of those with high school and/or some college between those with an advanced/professional degree was found to be statistically different.

'I would like my child to later train in [soccer/baseball]' $(F[2,132]=5.57, M S E=1.30, p$ $=.005)$ was rated highest by those with high school and/or some college $(M=3.15, S D=1.20$. $)$ followed by those with a bachelor's degree $(M=2.86, S D=1.24)$ and then by those with an advanced/professional degree $(M=2.35, S D=1.05)$. According to the post-hoc test, the differences between those with high school and/or some college compared to those with a bachelor's degree and between those with a bachelor's degree compared to those with an advanced/professional degree was found to not be statistically significant. However, the comparison of those with high school and/or some college between those with an advanced/professional degree was found to be statistically different.

'Sport follows certain rules' $(F[2,132]=5.79, M S E=1.39, p=.004)$ was rated highest by those with high school and/or some college $(M=4.22, S D=1.12)$ followed by those with a bachelor's degree $(M=4.02, S D=1.12)$ and then by those with an advanced/professional degree 
$(M=3.24, S D=1.24)$. According to the post-hoc test, the differences between those with high school and/or some college compared to those with a bachelor's degree and between those with a bachelor's degree compared to those with an advanced/professional degree was found to not be statistically significant. However, the comparison of those with high school and/or some college between those with an advanced/professional degree was found to be statistically different.

\section{Parents' motivations for enrollment between children genders. A one-way ANOVA} was run between respondent groups with male children $(n=107)$ and female children $(n=27)$. The hypothesis for this analysis was that parents' motivations for enrollment may be dependent on child's gender. No statistically significant differences were found.

\section{Parents' motivations for enrollment rankings between children's age groups. Groups} were made based on the Long-Term Athlete Development Model age group stages that change the focus of sport participation (Canadian Sport for Life, 2005). In the earlier stages, represent by the younger group of $6-8$ year olds, the focus is on fun, the development of foundational movement skills, and physical literacy. Whereas the next stage, represented by the $9-12$ year olds, the focus shifts towards a sport specific skill development and possible specialization (Canadian Sport for Life, 2005). A one-way ANOVA was run between respondent groups with children aged $6-8$ years old $(n=55)$ and children age $9-12$ years old $(n=80)$. The hypothesis for this analysis was that parents' motivations for enrollment may be dependent on the age of their child. However, no statistical significances were found.

\section{Influential Factors on Parents Youth Sport Program Selection}

In addition to the provided list of 10 possible influential factors that might impact parents when making for youth sport program enrollment decisions, parents were given the option to list any additional influencing factors that they felt were important but not reflected in the provided 
list (see Appendix E). From the open ended response option, 124 different raw data points from the total 135 different participants were collected and entered into an Excel spreadsheet for analysis.

The 124 'other influence' responses provided by participants were content analyzed and categorized into meaningful data units. The qualitative data were separated and analyzed using an inductive coding process (Corbin \& Strauss, 1990). This approach allowed for the data to produce emerging themes, since there was no hypothesis to accurately predict what parents perceived as additional influencing factors. The researcher recruited a peer debriefer with prior qualitative experience and expertise in this analysis method. Two meetings were held to discuss the inductive coding process prior to analysis. The research and peer debriefer coded the raw data separately, and compared coding notes and memos. The qualitative process involved grouping raw data points together based on commonalities to produce emergent themes. Higherorder thematic titles were chosen based on over-arching commonalities between raw data and the then between lower-order themes. Differences in the coding process were discussed and explored and thematic titles were finalized when an inter-coder agreement of $90 \%$ consensus was reached on all codes.

A total of fourteen lower order themes emerged and were organized into seven high-order themes. The higher-order themes, in order of response size, were 'interest in sport,' 'seeking specific outcomes,' 'barriers for program selection,' 'engagement in physical activity,' 'developing social connections,' 'knowledge of programs,' and 'fun/enjoyment' (see Appendix $\mathrm{K})$.

The higher-order theme 'interest in sport' was comprised of three lower-order themes: 'child expressed interest,' 'parent's influence,' and 'non-family influence.' Each lower-order 
theme emerged from commonalities within the raw data. For example, 'he likes baseball,' 'my child wanted to play soccer,' and 'my child was interested in the sport,' were grouped together into 'child expressed interest' based on the sport specific want/interest in participating. The 'parent's influence' lower order theme represented raw data points that dealt with parent's views of talent identification, playing time as it related to skill development and ease of commitment. Examples of raw data points include 'my son has excelled at it,' 'baseball has a longer season with more games and practices than other sports,' and 'little travel involved in the recreational league.' The third lower-order theme of 'non-family influence' had its own theme based on the influence of neither the child nor the parents in choosing the sport in which to participate.

The higher-order theme 'seeking specific outcomes' included four lower-order themes: 'parent expectations of participation,' 'character building,' 'sport cross-training,' and 'safety concerns.' Each lower-order theme emerged from grouping similar raw data together. For example, within 'parent expectations of participation' participants wrote items like 'to have my child experience a team sport,' 'competition is good for future success,' or 'development of motor skills.' These data points expressed certain sport related skills for their child to gain through the participation of youth sport. The lower-order theme of 'character building' grouped raw data points that were similar based on respondents who expressed non-sport skills to be developed through sport participation. Some examples of raw data points include, 'teamwork,' will build his confidence,' and 'discipline.' 'Sport cross-training' was another lower-order theme based on specific physical skills respondents wished their child to develop but also how those skills would be transferable to other sports in the future. Raw data points were similar to 'baseball will help develop good eye-hand coordination for lacrosse' within the lower order theme of 'sport cross-training.' The final lower-order theme of 'safety concerns' emerged from 
the raw data points that expressed respondents wish for their children to be safe while also experiencing youth sport. Examples of thematic raw data include 'baseball is the least likely to cause serious injury,' and 'safe sport compare to some of the more contact sports'.

The higher-order theme of 'barriers for program selection' had only one lower-order theme of 'limited options.' All responses within this lower-order theme pointed towards the limited or non-existent options of both of these sports within the surveyed town. Some examples of raw data include 'it's the only league in town,' 'no other baseball group available,' or 'no other league options.'

The higher-order theme of 'engagement in physical activity' had two lower-order themes of 'staying active/exercising' and 'free-time usage.' The lower-order theme of 'staying active/exercising' emerged based on the similar responses of respondents who discussed being active, staying active, or exercising. Some examples of raw data grouped into this lower theme include 'staying fit and active,' 'to keep him physically fit,' or 'good exercise.' The lower-order theme of 'free-time usage' emerged from responses based on the mention of time and structuring that the respondents seem to have over their child's schedule. Some examples of thematic raw data points include 'it's a summer activity that rarely interferes with school activities,' and 'my child will get exercise and spend her time in a useful manor'.

The higher-order theme of 'developing social connections' also had two lower-order themes which were 'friendship building' and 'family bond.' The lower-order theme of 'friendship building' emerged based on the similar responses focusing on the social aspect of sport participation. Whether it being making new friends or maintaining and building current friendships already in place. Some examples of raw data grouped within this lower order theme include 'my child has friends that also played,' 'developments new relationships,' and 'to make 
new friends.' In contrast to the lower-order theme of 'family bond' were responses which indicated a familial influence and bond within sport specific participation. Some examples of raw date include 'I like soccer and wanted my son to be involved in a great sport,' 'It is a sport my whole family enjoys, not just one or two people,' and 'my whole family has played baseball.'

The higher-order theme of 'knowledge of programs' only had one lower-order theme of 'previous program experience.' These raw data points were grouped based on prior positive experiences with the enlisted program. Examples of raw data points include 'my son has participated in program before,' 'my son liked soccer last season,' or 'positive past experience with program.'

The final higher-order theme of 'fun/enjoyment' also only had one lower-order theme, with the same name. Respondents were not sport specific with these responses but expressed their child's enjoyment while participating in general. In other words, the purpose was to enjoy themselves and not necessarily participating in a specific sport. Examples of raw thematic data include 'to have fun,' 'she has a lot of fun,' and 'enjoyment'.

The seven high-order themes were added to the provided list of 10 possible influential factors to determine the most influential factors within this sample. Of the 135 parents who completed the survey, $89.6 \%(n=121)$ ranked their top decision making influence. Eighty-seven percent of respondents $(n=118)$ provided their top two influences for program selection, $75.6 \%$ $(n=102)$ ranked their top three, $54.1 \%(n=73)$ ranked their top four influential factors and $66.7 \%(n=90)$ ranked the top five most influential factors in their program selection decision making process. Based on low response rates overall, only the top five most influential factors could be accurately determined. The top most influential factors were: 'interest in Sport' $(n=$ $27)$, 'close to home' $(n=17)$, 'child has friends within this youth sport organization $(n=15)$, 
'positive reputation of coaches within this youth sport program' $(n=9)$, and 'barriers for program selection' $(n=8)$ (see Appendix L). 


\section{Discussion}

\section{Summary of Findings}

The main focus of this study was to expand the body of knowledge regarding parents and their choice to enroll their children in youth sport. What do parents want their child to gain from participating in a specific youth sport program? What influences them to choose those programs? The findings of this study, in general, are similar to previous findings in the youth sport literature (Hutchinson et al., 2008; Kurnik et al., 2013; Schwab et al., 2010; Tomik et al., 2012). Parents rated and ranked both motivational factors for enrollment and influential factors for program selection. While some of these factors appear to be similar, especially regarding the qualitative survey data, it is important to note that the program selection decision process for parents has, to date, not yet been widely explored.

An interesting correlation of responses between two influential factor themes was found within the results. Certain responses grouped within 'barriers for program selection', a number of parents reported 'limited options' as influential factors and were specific to baseball. This is particularly interesting since parents chose programs seemingly based on sport specific availability. Also, many 'child expressed interest' responses were sport specific, again to baseball. These 'child expressed interest' responses combined with the amount of 'limited options' responses, both being specific to baseball, indicates that within this sample community, only one baseball league was available for participation.

Youth sport parents' enrollment motivations. The first research question this study sought to answer was what motivates parents to enroll their child in a specific youth sport program. The current literature suggests that physical activity and the potential benefits of sport participation are the central motivational factors (Holt et al., 2009; Hutchinson et al., 2003; 
Kurnik et al., 2013; Schwab et al., 2010; Tomik et al., 2012). However, this study found that the highest motivations for sport enrollment were based on the parents' perceptions of their child's enjoyment for being active. This is similar to the findings of Kurnik et al. (2013) which suggest that enrollment motivations rely on child's enjoyment of participation as well as the potential benefits of physical activity. The high rating of child's enjoyment is also similar to the findings in Dorsch et al. (2009), where parents reported that they wanted "the best possible youth sport experience" for their child (p. 454). This is consistent with the highest rated motivations for enrollment in this study being centered on child's engagement and enjoyment rather than what parent's expect their child to gain from participation (see Appendix F).

Additionally, the overall findings suggest that general assumptions of sport participation related benefits were important as motivations for enrollment. While the link between being physically active and health-related benefits have been discussed (Beets \& Pitetti, 2005; Dhurup, 2012), it has also been suggested that younger athletes should participate in sport with "selfreferenced outcomes" (ICCE, 2013, p. 53; see also: Blom et al., 2013; Canadian Sport for Life, 2005). Other assumed benefits (e.g. self-confidence, productive use of free time, and discipline), were also found to be rated high over all motivational factors. These findings mirror previous reports that suggest these character building traits can be facilitated by participating in sport (Blom et al., 2013; Hutchinson et al., 2003), but are more likely to occur in a supervised environment from a qualified coach (Blom et al., 2013; ICCE, 2013). Similarly, it has been shown that when there is a qualified coach providing instruction, sport participation can increase the child's self-esteem, self-confidence, and overall enjoyment (Smith et al., 1979; see also Barnett et al., 1992; Smith et al., 2007; Smith \& Smoll, 1990). So, does a coach play a role as a motivational factor for enrollment in youth sport programs? Unfortunately, that question cannot 
be answered either way within this particular instruments' findings. It does seem that within this sample, parents are motivated and may expect, some of those outcomes to be gained by their child while participating in these programs, regardless of coaching qualifications.

Means for skill development based motivations, both general and sport specific, were confined to the middle of the overall ranking list (see Appendix F). The fact that these motivations were not list as the highest suggest that parents are following, but not completely, the recommendations of national (Blom et al., 2013) and international (ICCE, 2013) sport organization for what the focus of youth sport should be. As discussed previously these early stages of youth sport should be focused on enjoyment, fun, and building upon physical literacy skill developed earlier (Canadian Sport for Life, 2005). Whether the parents are doing this by coincidence, purposefully, or have been informed in some other way cannot be stated for certain. This could also be due to that this study focused on participation youth sport programs and not any or all youth sport programs.

Other notable findings suggest that sport specific experiences and development seemed to be not as important as general sport participation (i.e. motivational factors that were sport specific were ranked, at highest, a 14 out of 30 motivational factors; see Appendix F). As Tomik et al. (2012) suggests multiple sport related experiences increase attitudes about participation in general and are likely to show continual participation. As Dixon et al. (2008) also suggests, early familial introduction and support of sport participation has the potential lead to lifetime sport involvement.

The lowest overall rankings for youth sport enrollment are similar to those found in Kurnik et al. (2013). Motivations for enrollment that are affected, or are influenced, by the parents themselves were rated low between both studies. This suggests that parents within both 
samples listen and respect their child's perceptions of sport participation, which has been previously found to affect enrollment decisions (McCullagh et al., 1993). It should be noted that parents' previous participation history in specific sports (i.e. whether or not they had played soccer/baseball) was also a low motivational enrollment factor. This suggests that this samples participants were acting not only as gatekeepers to specific sports but also as supportive guides to increase the number of sport related experiences for their children (Dixon et al., 2008; Dorsch et al., 2009; Holt et al., 2009). Parents in this study seemed to want their child to experience sport in general.

Motivations for enrollment according to subgroup analyses. The multiple subgroup analyses suggest that certain variables can predict parents' motivations for enrollment. Similar to previous literature (Kurnik et al., 2013; Tomik et al., 2012), this study found that parents' gender, age, and educational level play a role on specific motivations for sport enrollment. Those three demographic variables accounted for all of the variances for motivational factors for enrollment rankings (see Appendices G, H, I, and J). Also notable was that the parents across both sport programs appeared to have no differences between them, despite previous studies only focusing on one specific sport (Kurnik et al., 2013; Schwab et al., 2010; Smith et al., 1979; Smith \& Smoll, 1990). This suggests that parents are motivated by the same factors for enrollment regardless of sport choice.

This study also found no differences of motivational enrollment factors based on child's gender or age. Tomik et al. (2012) found that child's attitudes of sport participation differed between genders. It seems that parents are using the same motivations for enrollment regardless of having a son or daughter. It appears to be the same with regards to the child's age as well. According to the Long-Term Athlete Development model (Canadian Sport for Life, 2005), the 
age ranges within this sample should've produced some differences between younger and older groups. However, due to the small sample size and the limited sport programs surveyed, no such differences were found. This could also be attributed to the participation nature of the sport programs or just that these parents were not yet looking to have their children specialize within a sport.

Influential factors on parental youth sport program selection. The second study research question looked at what influenced parents decision making process when selecting a youth sport program. The number of additional open-ended responses from participants indicated that the provided 10 item list did not sufficiently represent the influences parents perceived as important when selecting youth sport programs. Second, the influencing factors for youth sport program selection were less related to expected outcomes and more related to social connections. There seem to be three points of view within youth sport literature on the influences of program selection. The first is the literature that suggests that the influences for program selection are centered on outcomes and benefits that are assumed to be automatically gained through sport participation (Holt et al., 2009; Kurnik et al., 2013; Tomik et al., 2012). The second point of view is youth sport literature that suggests enrollment selection is based on enjoyment and socialization within the program (Dorsch et al., 2009). While the third point of view is youth sport literature that suggests enrollment and selection are influenced by both outcome-based and socialization factors (Hutchinson et al., 2003; Schwab et al., 2010). This study's findings suggest that program selection relies more on the social influences (e.g. social connections within and to the program, child's interest in sport, parent's interest in sport) or the second point of view. However, the current study's' findings on influences for youth sport program selection has low 
generalizability since the highest response rate within just the number one ranked influence only reflected about one-fifth of the overall sample (see Appendix L).

Relationship between motivational and influential factors. The third research question this study sought to answer was what if any, relationship exists between the motivational factors for program enrollment and the influential factors for program selection. This research question sought to expand the literature on youth sport by exploring whether or not parents were selecting programs based on their motivations to enroll their child in youth sport. Exploring this relationship is a first step toward answering larger questions of 'why participate there?', or 'why NOT participate there?' A better understanding of either one of these questions could help reshape how youth sport programs are marketed and what they focus on. Due to the exploratory nature of this descriptive study (Campbell \& Stanley, 1963; Huck et al., 1974), the relationship between these two measures was only done at a descriptive level. In other words, did the motivational factors reflect similar ideas as those reported as influential factors for program selection?

The top motivations for program enrollment (see Appendix F) found in this study are similar to the top influential factors for program selection (see Appendix L). Within this study parents selected and enrolled their children in the youth sport programs that their children enjoy. This is similar to previous findings where parents have cited child's perceptions as factors for youth sport participation (McCullagh et al., 1993; Schwab et al., 2010; Smith et al., 1979). From these findings it is suggested that the motivational factors for program enrollment and the influential factors for program selection are approximately the same, their child. 


\section{Practical Implications}

Exploring how parents are selecting youth sport programs to enroll their children is important. The combination of high youth obesity levels (Ogden et al., 2014) and declining youth sport participation (Wallerson, 2014) is a recipe for a possible decline of this nation's athleticism. One way to influence and reverse these trends is to explore the selection process for youth sport participation from the parental decision making process perspective. Certain external motivations for youth sport program enrollment have been previously explored in literature (Hutchinson et al., 2008; Kurnik et al., 2013; Schwab et al., 2010; Tomik et al., 2012), this study's findings suggest that parents as a whole are supportive of their child's sport interests. Supportive parenting has been found to increase child's perceptions of enjoyment (Schwab et al., 2010) and develop their intrinsic motivation for continual sport participation (Dixon et al., 2008). Continual sport participation can lead to an increase in health-related benefits associated with sport participation (Beets \& Pitetti, 2005; Dhurup, 2012). In other words, parents support their child's choice and interest of sport, which then leads to higher level of enjoyment while participating. This leads to further sport participation creating a positive feedback loop of continual participation and reception of health-related benefits of being physically active. Since this study found that parents are influenced by their child's enjoyment and interest in sport participation, a program that is able to keep a child interested and motivated to improve will more likely retain and develop more young athletes.

The exploration of influential factors on parent's selection of a youth sport program is just as important as the exploration of parental motivations for enrollment in youth sport. This step of asking parents why they choose programs can help answer what parents may be thinking about prior to youth sport participation. The previously reported parental motivations for 
enrollment have been centered on specific outcomes parents wished their child to gain (Dorsch et al., 2009; Holt et al., 2009; Kurnik et al., 2013; Schwab et al., 2010). So, it would stand to reason that similar outcome centered influences for program selection would be present. This study's findings on some of the influential factors are similar to general sport participation enrollment (i.e.: fun/enjoyment, physical development, character development), but specific program selection, seems determined more from family- or community-based factors. Sport interests of the child/family, sport specific options, the location of a program in relation to home, and affordability of program seemed to be the largest factors of youth sport program selection.

However, the responses varied over the 17 possible influences for program selection. As noted before, the most ranked top influence had roughly one-fifth of the overall sample. While this does not provide a good foundation for generalizability, it does provide a foundation of what needs explored further. As noted earlier, the combination of responses grouped within 'barriers

for program selection' and those grouped within 'child expressed interest' being baseball specific indicate a singular baseball program in the sample community. Therefore, if a child wanted to play baseball, parents joined that league.

\section{Limitations}

While this study contributes to the literature on parental decision making regarding their children's youth sport participation, as with any study, it is important also to consider study limitations. This study was of pre-experimental design as a descriptive study (Campbell \& Stanley, 1963; Huck et al., 1974). Huck et al. (1974) point out that the "most obvious weakness of this design is the absence of control" (p. 227), both for internal and external validity. Internal validity concerns are specific to the study sample and the instruments used to collect data. The previous use of the 30-item questionnaire, modified from Kurnik et al. (2013), did offer some 
internal validity of the results. However, the use of the 10-item list as an instrumentation can only offer descriptive data for future exploration. External validity was also reduced based on this exploratory study. The motivations and influences for program enrollment and selection only reflect the sample within the study. The nature of the study design limits the generalizability of the findings across the broader youth sport culture in the United States. As such, the results found should only be used as a possible baseline for program selection within youth participation sport.

Timing of the data collection was a study limitation. The study was conducted during a seasonal sport transition period and as such sought to collect at the very end of the season or the very beginning of the offseason. This limited quick and consistent communication with program administration, typically volunteers, in gaining access to parents of enrolled child athletes. It also limited data to parents looking back (i.e. after the fact) at initial motivations for enrollment. Data collection during youth sport enrollment might allow for a better response rate, a broader number of programs enlisted, and increase the accuracy of parent's reporting of their enrollment motivations and influencing factors. Collection during this sign-up period could be done face-toface to increase overall sample numbers, which could additionally provide a more accurate reflection of 'in the moment' data. This would also include any families that do not have regular access to the internet for online recruitment and collection.

Only two programs were surveyed for this study. This was due to the recruitment of participation based youth sport only and was limited again to the time of year. Data collection across multiple sports could produce more thorough investigation of influential factors for program selection. Doing this would also expand the time of data collection to increase the response rate. 
Demographics of the sample population were also a limit for this study. The sample population had a high level of education with $48.9 \%$ reporting a graduate degree or higher (see Appendix D). According to the U.S. Census Bureau (2014), roughly 16\% of the population over the age of 25 within the United States has a graduate degree or higher. A survey done in a different area of the country could produce different results based solely on educational levels.

Socioeconomic status was not considered as a demographic option for participants to report. This limited findings that may have been dependent on levels of household income. A further demographic limitation was the high number of participants reported having male children. This possible caused the findings to be biased for male youth athletes instead of youth athletes in general.

\section{Future Research}

Future research is suggested to explore further the influential factors for parental youth sport program selection. There has been previous research on parental motivational factors for youth sport program enrollment already (Hutchinson et al., 2008; Kurnik et al., 2013; Tomik et al., 2012), which all have found very similar results. The decision-making process and the accompanying influences on parents for program selection have, to date, not been thoroughly explored. To better understand why parents are choosing specific programs, or possibly specific sports, over others, this area needs to be expanded. In order to do this, future studies could modify and/or expand the influential factors for parental youth sport program selection questionnaire to include some of the qualitative data themes. This questionnaire could also be used as a jumping point to guide focus groups of parents. Such focus groups could allow parents to identify and create a more complete list of all possible influential factors, rather than a researcher creating another incomplete list. 
Another suggestion for further exploration is conducting multiple surveys within one study. A study that could encompass one full year to capture each possible sport in a community would provide more complete data. This could address whether or not parents are choosing different sport specific programs for different reasons (e.g. 'child's interest in sport' vs. 'parent's influence'). Future research could go in a different direction and focus on one sport but survey a wider sample population across multiple communities. This type of study could have wider generalizability across the country, as long as all demographic areas are covered. This would include urban, suburban, and rural communities along with multiple areas of affluence or poverty.

\section{Conclusion}

Parents have continually responded as wanting their child to gain health-related benefits, physical development, and/or character development from participating in youth sport (Holt et al., 2009; Hutchinson et al., 2008; Kurnik et al., 2013; Tomik et al., 2012). However, based on the findings of this study, parents are choosing programs based on what their child wants to do, or what is readily available within their community. Yet, as research shows (Smith et al., 1979; see also Blom et al., 2013; ICCE, 2013) all of these areas (e.g. health-benefits, skill/character development, enjoyment, socialization) are dependent on the quality of coaching children are exposed to. Parents are expecting certain outcomes for their children but are not looking for those within readily available youth sport programs. A better understanding of why parents put their children in specific youth sport programs could eventually help change the way youth sport coaches are vetted and educated. More importantly, parents are not specifically looking for qualified coaches to facilitate the outcomes that they expect. In other words, they need to prioritize their selection of their available youth sport programs. Three elements that influence 
the quality of coaches within youth sports are: what parents want, how they are making program selections, and how/what programs are offered in the area. Minimizing the gaps between these three elements could support a national change to encourage coaching education within our youth sport culture. 


\section{References}

Aspen Institute. (2014). Project play. Retrieved from http://www.aspenprojectplay.org/the-facts

Barcelona, R. J., \& Young, S. J. (2010). The role of municipal park and recreation agencies in enacting coach and parent training in a loosely coupled youth sport program. Managing Leisure, 15, 181-197. doi: 10.1080/13606719.2010.483830.

Barnett, N. B., Smoll, F. L., \& Smith, R. E. (1992). Effects of enhancing coach-athlete relationships on youth sport attrition. The Sport Psychologist, (6), 111-127.

Beets, M. W., \& Pitetti, K. H. (2005). Contribution of physical education and sport to healthrelated fitness in high school students. Journal of School Health, 75(1), 25-30. doi: 10.1111/j.1746-1561.2005.tb00005.x.

Blom, L., Bronk, K., Coakley, J., Lauer, L., \& Sawyer, T. (2013). Maximizing the benefits of youth sport. Journal of Physical Education, Recreation \& Dance, 84(7), 8-13.

Campbell, D. T., \& Stanley, J. C. (1963). Experimental and quasi-experimental designs for research. Chicago, IL: Rand McNally College Publishing Company.

Canadian Sport for Life. (2005). Long-term athletic development model. Retrieved from http://canadiansportforlife.ca/learn-about-canadian-sport-life/ltad-stages

Corbin, J., \& Strauss, A. (1990). Grounded theory research: Procedures, canons, and evaluative criteria. Qualitative Sociology, 13(1), 3-21. doi: 10.1007/BF00988593.

Dhurup, M. (2012). A dimensional analysis of the benefits derived from physical activity participation among university students and variation in terms of gender. African Journal of Physical, Health Education, Recreation and Dance, 18(3), 614-627. 
Dixon, M. A., Warner, S. M., \& Bruening, J. E. (2008). More than just letting them play: Parental influence on women's lifetime sport involvement. Sociology of Sport Journal, $25,538-559$.

Dorsch, T. E., Smith, A. L., \& McDonough, M. H. (2009). Parents' perceptions of child-to-parent socialization in organized youth sport. Journal of Sport and Exercise Psychology, 31, 444-468.

Forneris, T., Whitley, M. A., \& Barker, B. (2013). The reality of implementing a communitybased sport and physical activity programs to enhance the development of underserved youth: Challenges and potential strategies. Quest, 65, 313-331. doi:

10.1080/00336297.2013.773527.

Gearity, B. T. (2012). Poor teaching by the coach: A phenomenological description from athletes" experience of poor coaching. Physical Education and Sport Pedagogy, 17(1), 79-96. doi: 10.1080/17408989.2010.548061.

History of Pop Warner. (2015). Retrieved from http://www.popwarner.com/About_Us/history.htm

Holt, N. L., Tamminen, K. A., Black, D. E., Mandigo, J. L., \& Fox, K. R. (2009). Youth sport parenting styles and practices. Journal of Sport and Exercise Psychology, 31, 37-59.

Huck, S. W., Cormier, W. H., \& Bounds, W. G. (1974). Reading statistics and research. New York, NY: Harper \& Row, Publishers, Inc.

Hutchinson, S. L., Baldwin, C. K., \& Caldwell, L. L. (2003). Differentiating parent practices related to adolescent behavior in the free time context. Journal of Leisure Research, $35(4), 396-422$. 
International Council for Coaching Excellence (2013). International sport coaching framework. (Vol. 1.2, pp. 37-42). Champaign, Illinois: Human Kinetics.

Kanters, M. A., Bocarro, J., \& Casper, J. (2008). Supported or pressured? An examination of agreement among parent's children on parent's role in youth sport. Journal of Sport Behavior, 31(1), 64-80.

Kurnik, J. F., Kajtna, T., Bedenik, K., \& Kovac, M. (2013). Why parents enroll their children in recreational gymnastics progammes " at the beginning of their education. Science of Gymnastics Journal, 5(2), 41-52.

LaVetter, D., \& Stahura, K. A. (2010). Negligent hiring in youth sports: Background screening of volunteers. YouthFirst: The Journal of Youth Sports, 5(1), 9-15.

Light, R. L. (2010). Children's social and personal development through sport: A case study of an Australian swimming club. Journal of Sport and Social Issues, 34(4), 379-395. doi: $10.1177 / 0193723510383848$.

Little league historical timeline. (2015). Retrieved from http://www.littleleague.org/Little_League_Big_Legacy.htm

Lumpkin, A. (2013). Teaching values through youth and adolescent sports. Strategies: A Journal for Physical and Sport Educators, 21(4), 19-23. doi: 10.1080/08924562.2008.10590780

McCullagh, P., Matzkanin, K. T., Shaw, S. D., \& Maldonado, M. (1993). Motivation for participation in physical activity: A comparison of parent-child perceived competencies and participation motives. Pediatric Exercise Science, 5, 224-233.

National coaching report. (2008). Oxon Hill, MD: National Association for Sport and Physical Education. 
Nunomura, M., \& Oliveira, M. S. (2013). Parents' support in the sports career of young gymnasts. Science of Gymnastics Journal, 5(1), 5-17.

Ogden, C. L., Carroll, M. D., Kit, B. K., \& Flegal, K. M. (2014). Prevalence of childhood and adult obesity in the United States, 2011-2012. Journal of the American Medical Association, 311(8), 806-814. doi:10.1001/jama.2014.732.

Pennsylvania State Association for Health, Physical Education, Recreation and Dance (2008). New national coaching report stresses importance of qualified coaches for every athlete. Pennsylvania Journal of Health, Physical Education, Recreation and Dance, 78(3), 29.

Rose, K. K., \& Elicker, J. (2008). Parental decision making about child care. Journal of Family Issues, 29(9), 1161-1184. doi: 10.1177/0192513X07312103.

Schwab, K. A., Wells, M. S., \& Arthur-Banning, S. (2010). Experiences in youth sports: A comparison between players' and parents' perspectives. Journal of Sport Administration \& Supervision, 2(1), 41-51.

Seifried, C. (2008). Examining punishment and discipline: Defending the use of punishment by coaches. Quest, 60, 370-386. doi: 10.1080/00336297.2008.10483587

Smith, R. E., \& Smoll, F. L. (1990). Self-esteem and children's reactions to youth sport coaching behaviors: A field study of self-enhancement processes. Developmental Psychology, 26(6), 987-993. http://dx.doi.org/10.1037/0012-1649.26.6.987.

Smith, R. E., Smoll, F. L., \& Cumming, S. P. (2007). Effects of a motivational climate intervention for coaches on young athletes' sport performance anxiety. Journal of Sport and Exercise Psychology, 29, 39-59. 
Smith, R. E., Smoll, F. L., \& Curtis, B. (1979) Coach effectiveness training: A cognitivebehavioral approach to enhancing relationship skills in youth sport coaches. Journal of Sport Psychology, 1, 59-75.

Telama, R., Laakso, L., Nupponen, H., Rimpela, A., \& Pere, L. (2009). Secular trends in youth physical activity and parents' socioeconomic status from 1977 to 2005. Pediatric Exercise Science, 21, 462-474.

Tomik, R., Olex-Zarychta, D., \& Mynarski, W. (2012). Social values of sport participation and their significance for youth attitudes towards physical education and sport. Studies in Physical Culture and Tourism, 2(2), 99-104.

U.S. Census Bureau. (2014). Educational attainment in the United States: 2014. Retrieved from https://www.census.gov/hhes/socdemo/education/data/cps/2014/tables.html

U.S. Census Bureau. (2015). U.S. population clock. Retrieved from http://www.census.gov/popclock/data_tables.php?component=pyramid

Wallerson, R. (2014, Jan 31). Youth participation weakens in basketball, football, baseball, soccer. Wall Street Journal.

Watson II, J. C., Connole, I., \& Kadushin, P. (2011). Developing young athletes: A sport psychology based approach to coaching youth sports. Journal of Sport Psychology in Action, 2, 113-122. doi: 10.1080/21520704.2011.586452 


\section{Appendix A}

IRB Approval Letter

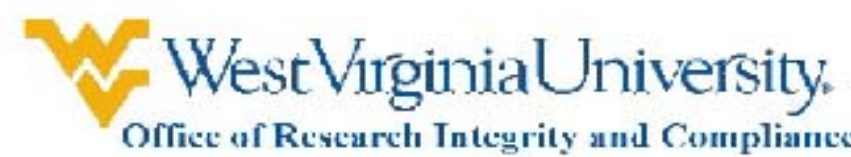

\section{Acknowledgement Letter Exempt Initial Protocol Review}

Action Date

To

From

Approval Date

Expiration Date

Subject

Protocol Number

Title
06/01/2015

Kristen Dieffenbach

WVU Office of Research Integrity and Compliance

$06 / 01 / 2015$

$05 / 31 / 2018$

Acknowledgement Letter Exempt Initial Protocol Review

1504668355

Influences on parents decision making for enrollment in youth sports

The above-referenced study was reviewed by the West Virginia University Institutional Review Board IRB and was granted exemption in accordance with 45 CFR 46.101.

" This research study was granted an exemption because the Research involves educational tests, survey procedures, interview procedures or observation of public behavior and (i) information obtained is recorded in such a manner that human subjects cannot be identified, directly or through identifiers linked. to the subjects; and (ii) any disclosure of the human subjects responses outside the research could not reasonably place the subjects at risk of criminal or civil liability or be damaging to the subjects financial standing, employability, or reputation [45 CFR 46.101(2)]. All exemptions are only good for three years. If this research extends more than three years beyond the approved date, then the researcher will have to request another exemption. The following documents have been acknowledged for use in this study and are available in the WVU+ke system:

Documents reviewed and/or approved as part of this submission:

Introduction Email to particpants.docx 2015-05-22-04:00

SURVEY.docx: 2015-05-22-04:00

Introduction Email to particpants.doex: 2015-05-29-04:00

Introduction Email to particpants.docx: 2015-05-29-04:00 
Documents for use in this study have been acknowledged and are available in the WVUkc system in the Notes and Attachments section of your protocol

The Office of Research Integrity and Compliance is here to provide assistance to you from the initial submission of an IRB protocol and all subsequent activity. Please feel free to contact us by phone at 304.293 .7073 with any question you may have. Thank you.

WVU Office of Research Integrity and Compliance

Date:06/01/2015

Signed:

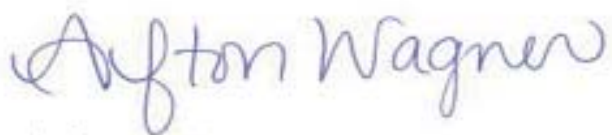

Afton Wagner IRB Administrator 


\section{Appendix B}

Introduction Email to Program Administrators

To whom it may concern:

My name is Karl Zang and I am a graduate student at West Virginia University. For my Master's Thesis I am examining the influential factors parents use in determining a youth sport program to enroll their child.

I would like to ask your permission to contact parents who are registered in your program. After permission from [Program Director] has been granted, I will ask [Program Director] for access to a parental email list for participant recruitment.

The survey is hosted online through Qualtrics ${ }^{\circledR}$. West Virginia University's Institutional Review Board acknowledgement of this project is on file. There are no known risks, it is completely anonymous, and voluntary. The data collected will provide useful information regarding parental selection of youth sport programs. Thank you for taking the time to assist me in my educational endeavors.

If you are not satisfied with the manner in which this study is being conducted, you may report (anonymously if you so choose) any complaints to Dr. Kristen Dieffenbach whose contact information is also listed below.

Sincerely,

Karl Zang

412.225.7702 Karl.Zang@,mail.wvu.edu

Dr. Kristen Dieffenbach

304.293.0847 Kristen.Dieffenbach@,mail.wvu.edu 


\author{
Appendix C \\ Recruitment Email to Participants
}

Dear Participant:

My name is Karl Zang and I am a graduate student at West Virginia University. For my Master's Thesis I am examining the influential factors parents use in determining a youth sport program to enroll their child. Because of your enrollment in [sport program] I am inviting you to participate in this study by completing the survey, found here: [online link].

The questionnaire linked above will require approximately 10 minutes to complete. There is no compensation for responding nor is there any known risk. You must be 18 years of age or older to participate. In order to ensure all information will be anonymous and confidential, please do not include your name. Copies of the project will be provided to my West Virginia University instructor and to the [program director]. If you choose to participate in the project, please answer all the questions as honestly as possible. Participation is strictly voluntary and you may refuse to participate at any time. West Virginia University's Institutional Review Board acknowledgement of this project is on file.

Thank you for taking the time to assist me in my educational endeavors. The data collected will provide useful information regarding parental selection of youth sport programs. If you would like a copy of this study please contact me via email. Completion of the online questionnaire will indicate your willingness to participate in this study. If you require additional information or have questions, please contact me at the number or email address listed below.

If you are not satisfied with the manner in which this study is being conducted, you may report (anonymously if you so choose) any complaints to Dr. Kristen Dieffenbach whose contact information is listed below.

Sincerely,

Karl Zang

412.225.7702 Karl.Zang@mail.wvu.edu

Dr. Kristen Dieffenbach

304.293.0847 Kristen.Dieffenbach@mail.wvu.edu 


\section{Appendix D}

Demographic Information of Parents and Their Children

\begin{tabular}{|c|c|c|c|c|c|c|}
\hline & $\underline{\mathrm{N}}$ & $\underline{\text { Min }}$ & $\underline{\operatorname{Max}}$ & $\underline{\mathrm{M}}$ & $\underline{\mathrm{SD}}$ & \\
\hline Parent's Age ${ }^{a}$ & 132 & 26.00 & 62.00 & 40.28 & 6.80 & \\
\hline \multirow[t]{2}{*}{ Child's Age } & 135 & 6.00 & 12.00 & 9.00 & 2.02 & \\
\hline & & Male & Female & & & \\
\hline Parent's Gender & 135 & 47 & 88 & & & \\
\hline Childs Gender ${ }^{\mathrm{a}}$ & 134 & 107 & 27 & & & \\
\hline Enrolled in Baseball ${ }^{\mathrm{a}}$ & 75 & 74 & 0 & & & \\
\hline \multirow[t]{2}{*}{ Enrolled in Soccer ${ }^{a}$} & 57 & 32 & 25 & & & \\
\hline & & $\begin{array}{l}\text { High school } \\
\text { /G.E.D. }\end{array}$ & $\begin{array}{l}\text { Associate's } \\
\text { Degree }\end{array}$ & $\begin{array}{l}\text { Bachelor's } \\
\text { Degree }\end{array}$ & $\begin{array}{l}\text { Master's } \\
\text { Degree }\end{array}$ & $\begin{array}{c}\text { Ph.D./ M.D./ } \\
\text { J.D./ Similar } \\
\underline{\text { Degree }}\end{array}$ \\
\hline Parent's Education Level & 135 & 17 & 10 & 42 & 34 & 32 \\
\hline
\end{tabular}

Note: ${ }^{\text {a }}$ denotes unspecified demographic data. These will not add up to the corresponding total of usable surveys $n=135$ 


\section{Appendix E}

Influencing Factors on Parent's Decisions for Youth Sport Enrollment Survey

\section{Organization:}

Sport:

\section{$\underline{\text { Part I: }}$}

We are interested in learning more about the youth sport experience. Please complete and consider your oldest child within the 6-12 year old age range who is participating in this youth sport program. Please answer all questions honestly and completely.

The first part of the survey is about you and your child.

\section{Tell us about you}

1) Your Gender: M $\mathrm{F}$

2) Your Age:

3) Education level (please circle one that fits best):

High school/GED Associates degree Bachelor's degree

Master's Degree $\quad \mathrm{PhD} / \mathrm{MD} / \mathrm{JD}$ or similar

Please tell us about your oldest child, within the 6-12 year old age range, who is participating in this youth sport program

4) Gender: $M$ $\mathrm{F}$

5) Age as of today:

6) What other organized youth sport activities has this child participated in?

\begin{tabular}{|l|l|l|l|l|l|l|}
\hline Baseball/softball & & Basketball & & Football & & Other: \\
\cline { 1 - 4 } Soccer & & Swimming & & Dance & & \\
\hline
\end{tabular}




\section{Part II}

Please rate the following motivations for enrolling your child in this youth sport program. Please keep in mind the child you described in Part I.

\begin{tabular}{|c|c|c|c|c|c|}
\hline & $\begin{array}{c}1=\text { not } \\
\text { at all } \\
\text { important }\end{array}$ & & & & $\begin{array}{c}5=\text { very } \\
\text { important }\end{array}$ \\
\hline Sport benefits the health of my child. & 1 & 2 & 3 & 4 & 5 \\
\hline My child will be in better physical condition. & 1 & 2 & 3 & 4 & 5 \\
\hline My child will spend free time in a useful way. & 1 & 2 & 3 & 4 & 5 \\
\hline My child will have fun at sport. & 1 & 2 & 3 & 4 & 5 \\
\hline My child likes to compete. & 1 & 2 & 3 & 4 & 5 \\
\hline Sport will serve as relaxation. & 1 & 2 & 3 & 4 & 5 \\
\hline My child will be fitter. & 1 & 2 & 3 & 4 & 5 \\
\hline My child enjoys sport. & 1 & 2 & 3 & 4 & 5 \\
\hline My child will make good friends when exercising. & 1 & 2 & 3 & 4 & 5 \\
\hline My child likes to play. & 1 & 2 & 3 & 4 & 5 \\
\hline Sport follows certain rules. & 1 & 2 & 3 & 4 & 5 \\
\hline My child needs exercise after school. & 1 & 2 & 3 & 4 & 5 \\
\hline Sport increase self-confidence. & 1 & 2 & 3 & 4 & 5 \\
\hline Sport will help him/her in future life. & 1 & 2 & 3 & 4 & 5 \\
\hline My child will look better. & 1 & 2 & 3 & 4 & 5 \\
\hline My child will acquire competitive experience. & 1 & 2 & 3 & 4 & 5 \\
\hline My child wished to participate in a sport. & 1 & 2 & 3 & 4 & 5 \\
\hline His/her friends also participate in sports. & 1 & 2 & 3 & 4 & 5 \\
\hline It will give me more free time. & 1 & 2 & 3 & 4 & 5 \\
\hline My child will be more confident. & 1 & 2 & 3 & 4 & 5 \\
\hline My child will acquire certain working habits & 1 & 2 & 3 & 4 & 5 \\
\hline My child will burn off excess energy. & 1 & 2 & 3 & 4 & 5 \\
\hline I would like my child to learn new skills. & 1 & 2 & 3 & 4 & 5 \\
\hline My child likes to exercise. & 1 & 2 & 3 & 4 & 5 \\
\hline (Soccer/Baseball) will develop his/her abilities.* & 1 & 2 & 3 & 4 & 5 \\
\hline His/her friends practice (soccer/baseball). ${ }^{*}$ & 1 & 2 & 3 & 4 & 5 \\
\hline (Soccer/Baseball) is interesting and attractive.* & 1 & 2 & 3 & 4 & 5 \\
\hline $\begin{array}{l}\text { I would like my child to later train in } \\
\text { (soccer/baseball).* }\end{array}$ & 1 & 2 & 3 & 4 & 5 \\
\hline $\begin{array}{l}\text { By participating in (soccer/baseball), he/she will } \\
\text { acquire basic motor skill, important for all } \\
\text { sports.* }\end{array}$ & 1 & 2 & 3 & 4 & 5 \\
\hline Because I used to play (soccer/baseball).* & 1 & 2 & 3 & 4 & 5 \\
\hline
\end{tabular}

Note:* denotes sport was piped in based on sport entered by parents at the beginning of the survey 


\section{Part III}

Thinking about your oldest child (age 6-12) who is enrolled in this youth sport program, please rank your top five (5) reasons, for selecting this specific youth sport program for your child with \#1 being the most important reason.

$1=$ the most important reason and then rank reasons 2-5 according to importance to you. You do not need to rank any of the responses in the provided list if they do not apply to you. Please use other to write in any reasons that were important to you that are not reflected in the provided list.

\begin{tabular}{|l|l|}
\hline & Convenience: close to home \\
\hline & Convenience: close to my child's school \\
\hline & Convenience: close to your work \\
\hline & $\begin{array}{l}\text { Offordable } \\
\text { Soccer/baseball organization)* }\end{array}$ \\
\hline & $\begin{array}{l}\text { Other children in the family have previously been in enrolled in programs within (this } \\
\text { soccer/baseball organization)* }\end{array}$ \\
\hline & Positive reputation of the coach your child works with \\
\hline & Positive reputation of the coaches within (this soccer/baseball organization)* \\
\hline & Positive reputation of the (soccer/baseball organization)* \\
\hline & My child has friends enrolled in (this soccer/baseball organization)* \\
\hline & Other: \\
\hline & Other: \\
\hline & Other: \\
\hline & Other: \\
\hline & Other: \\
\hline
\end{tabular}

Note:* denotes sport was piped in based on sport entered by parents at the beginning of the survey 


\section{Appendix F}

Overall Mean Ratings of Youth Sport Parents' Child Enrollment Motivations

\begin{tabular}{|c|c|c|c|}
\hline Motivations for Enrollment & $\mathrm{N}$ & M & $\mathrm{SD}$ \\
\hline My child will have fun at sport. & 135 & $4.72 *$ & 0.51 \\
\hline My child enjoys sport. & 135 & $4.59 *$ & 0.73 \\
\hline My child likes to play. & 135 & $4.58 *$ & 0.67 \\
\hline My child wished to participate in a sport. & 135 & 4.56 & 0.77 \\
\hline Sport increases self-confidence. & 135 & 4.48 & 0.79 \\
\hline Sport benefits the health of my child. & 135 & 4.39 & 0.86 \\
\hline My child will be in better physical condition. & 135 & 4.30 & 0.92 \\
\hline Sport will help him/her in future life. & 135 & 4.29 & 0.95 \\
\hline My child will be more confident. & 133 & 4.29 & 0.89 \\
\hline My child will spend free time in a useful way. & 135 & 4.23 & 0.87 \\
\hline I would like my child to learn new skills. & 135 & 4.22 & 0.91 \\
\hline My child will acquire certain working habits. & 135 & 4.10 & 0.90 \\
\hline My child will make good friends when exercising. & 135 & 4.06 & 0.99 \\
\hline My child will be fitter. & 133 & 4.05 & 0.99 \\
\hline $\begin{array}{l}\text { By participating in (soccer/baseball), he/she will acquire basic motor } \\
\text { skill, important for all sports. }\end{array}$ & 135 & 3.99 & 1.08 \\
\hline (Soccer/Baseball) will develop his/her abilities. & 134 & 3.97 & 0.97 \\
\hline Sport follows certain rules. & 135 & 3.77 & 1.22 \\
\hline My child likes to exercise. & 135 & 3.75 & 1.18 \\
\hline His/her friends also participate in sports. & 135 & 3.67 & 1.11 \\
\hline My child likes to compete. & 135 & 3.55 & 1.21 \\
\hline My child needs exercise after school. & 135 & 3.55 & 1.18 \\
\hline My child will burn off excess energy. & 135 & 3.46 & 1.21 \\
\hline My child will acquire competitive experience. & 135 & 3.39 & 1.22 \\
\hline (Soccer/Baseball) is interesting and attractive. & 134 & 3.22 & 1.33 \\
\hline His/her friends practice (soccer/baseball). & 135 & 3.16 & 1.28 \\
\hline Sport will serve as relaxation. & 135 & 3.05 & 1.20 \\
\hline I would like my child to later train in (soccer/baseball). & 135 & 2.67 & 1.18 \\
\hline My child will look better. & 134 & $1.99 * *$ & 1.06 \\
\hline Because I used to play (soccer/baseball). & 135 & $1.79 * *$ & 1.25 \\
\hline It will give me more free time. & 135 & $1.25 * *$ & 0.67 \\
\hline
\end{tabular}

Note: ${ }^{*}$ denotes highest three mean ratings, ${ }^{* *}$ denotes lowest three mean ratings 


\section{Appendix G}

Parental Motivations for Youth Sport Enrollment Differences between Parents' Genders

\begin{tabular}{llllllll}
\hline & Male & \multicolumn{1}{l}{ Female } \\
\hline Motivation & $\underline{\mathrm{M}}$ & $\underline{\mathrm{SD}}$ & $\underline{\mathrm{M}}$ & $\underline{\mathrm{SD}}$ & $\underline{F}$ \\
My child will acquire competitive experience. & 3.79 & 1.06 & 3.18 & 1.25 & $7.99^{* *}$ \\
I would like my child to learn new skills. & 3.94 & 1.05 & 4.38 & 0.79 & $7.44^{* *}$ \\
(Soccer/Baseball) will develop his/her abilities. & 3.60 & 1.08 & 4.17 & 0.84 & $11.78^{* * *}$ \\
Because I used to play (soccer/baseball). & 2.15 & 1.37 & 1.59 & 1.14 & $6.37^{*}$ \\
\hline
\end{tabular}

Note: ${ }^{*} p<.05$ two-tailed analysis, ${ }^{* *} p<.01, * * * p<.001$ 


\section{Appendix H}

Parental Motivations for Youth Sport Enrollment Differences between Parents' Age Groups

\begin{tabular}{|c|c|c|c|c|c|}
\hline & \multicolumn{2}{|c|}{$<39$} & \multicolumn{2}{|c|}{$40+$} & \\
\hline Motivation & $\underline{M}$ & $\underline{\mathrm{SD}}$ & $\underline{M}$ & $\underline{\mathrm{SD}}$ & $\underline{F}$ \\
\hline $\begin{array}{l}\text { By participating in (soccer/baseball), he/she will acquire } \\
\text { basic motor skill, important for all sports. }\end{array}$ & 4.19 & 1.06 & 3.76 & 1.09 & $5.19 *$ \\
\hline
\end{tabular}

Note: $* p<.05$ two-tailed analysis 


\section{Appendix I}

Parental Motivations for Youth Sport Enrollment Differences between Parents' Educational Level Groups

\begin{tabular}{|c|c|c|c|c|c|c|c|}
\hline \multirow[b]{2}{*}{ Motivations } & \multicolumn{2}{|c|}{$\begin{array}{l}\text { High School } \\
\text { and/or Some } \\
\text { College } \\
\end{array}$} & \multicolumn{2}{|c|}{$\begin{array}{l}\text { Bachelor's } \\
\text { Degree }\end{array}$} & \multicolumn{2}{|c|}{$\begin{array}{l}\text { Advanced/ } \\
\text { Professional } \\
\text { Degree } \\
\end{array}$} & \multirow[b]{2}{*}{$\underline{F}$} \\
\hline & $\underline{M}$ & $\underline{\mathrm{SD}}$ & $\underline{\mathrm{M}}$ & $\underline{\mathrm{SD}}$ & $\underline{\mathrm{M}}$ & $\underline{\mathrm{SD}}$ & \\
\hline Sport follows certain rules. & 4.22 & 1.12 & 4.02 & 1.12 & 3.42 & 1.24 & $5.79 * *$ \\
\hline I would like my child to learn new skills. & 4.56 & .641 & 4.40 & .767 & 3.97 & 1.02 & $5.53 * *$ \\
\hline (Soccer/Baseball) will develop his/her abilities. & 4.22 & .751 & 4.21 & .750 & 3.71 & 1.10 & $4.95 * *$ \\
\hline $\begin{array}{l}\text { I would like my child to later train in } \\
\text { (soccer/baseball). }\end{array}$ & 3.15 & 1.20 & 2.86 & 1.24 & 2.35 & 1.05 & $5.57 * *$ \\
\hline $\begin{array}{l}\text { By participating in (Soccer/Baseball), he/she } \\
\text { will acquire basic motor skill, important for } \\
\text { all sports. }\end{array}$ & 4.33 & .877 & 4.21 & .842 & 3.71 & 1.22 & $4.68 *$ \\
\hline
\end{tabular}

Note: ${ }^{*} p<.05$ two-tailed analysis, ${ }^{* *} p<.01$ 


\section{Appendix J}

Bonferroni Post-Hoc Test between Parents' Educational Level Groups

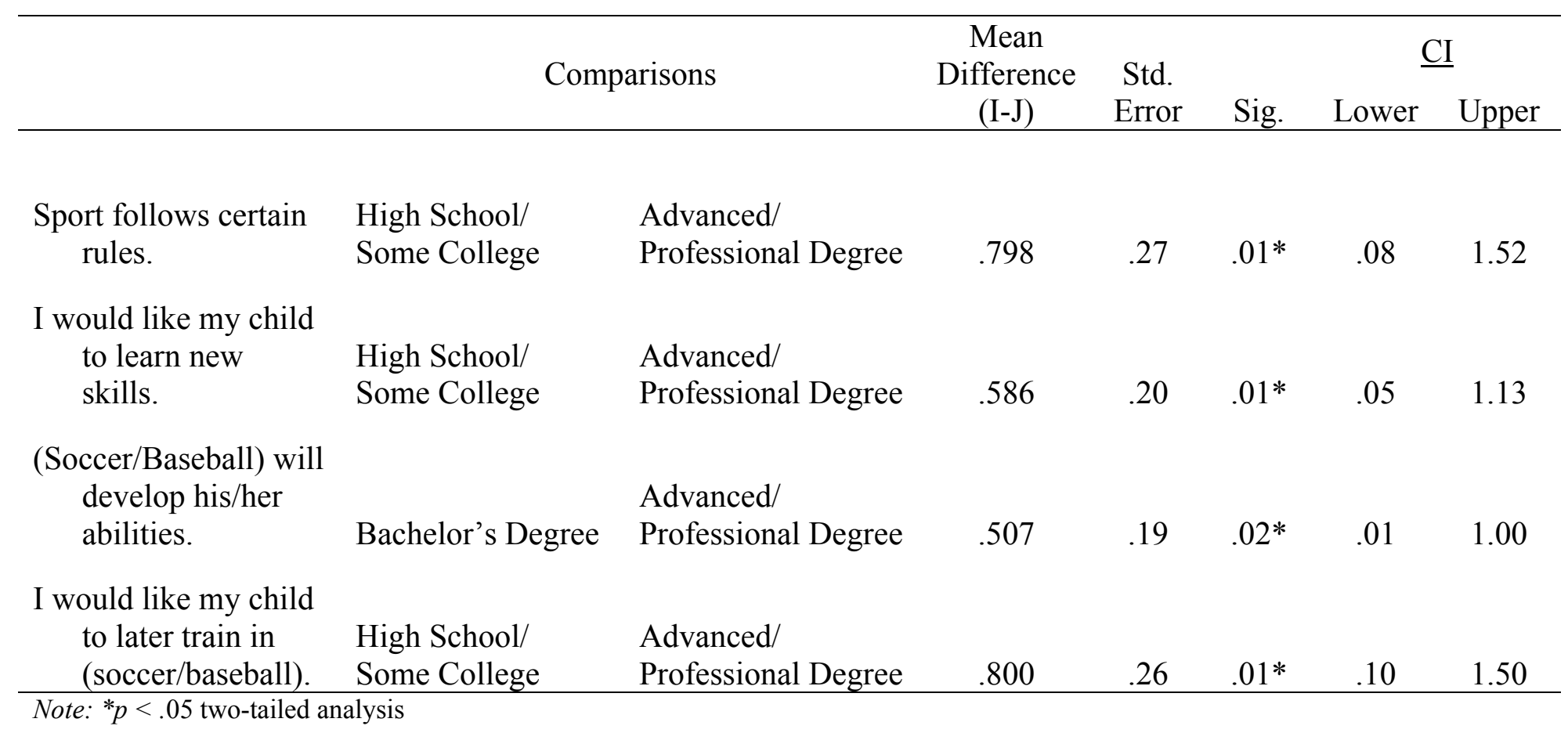




\section{Appendix K}

Breakdown of 'Other' Influential Factors Responses into Higher- and Lower-Order Themes with Total Number of Responses

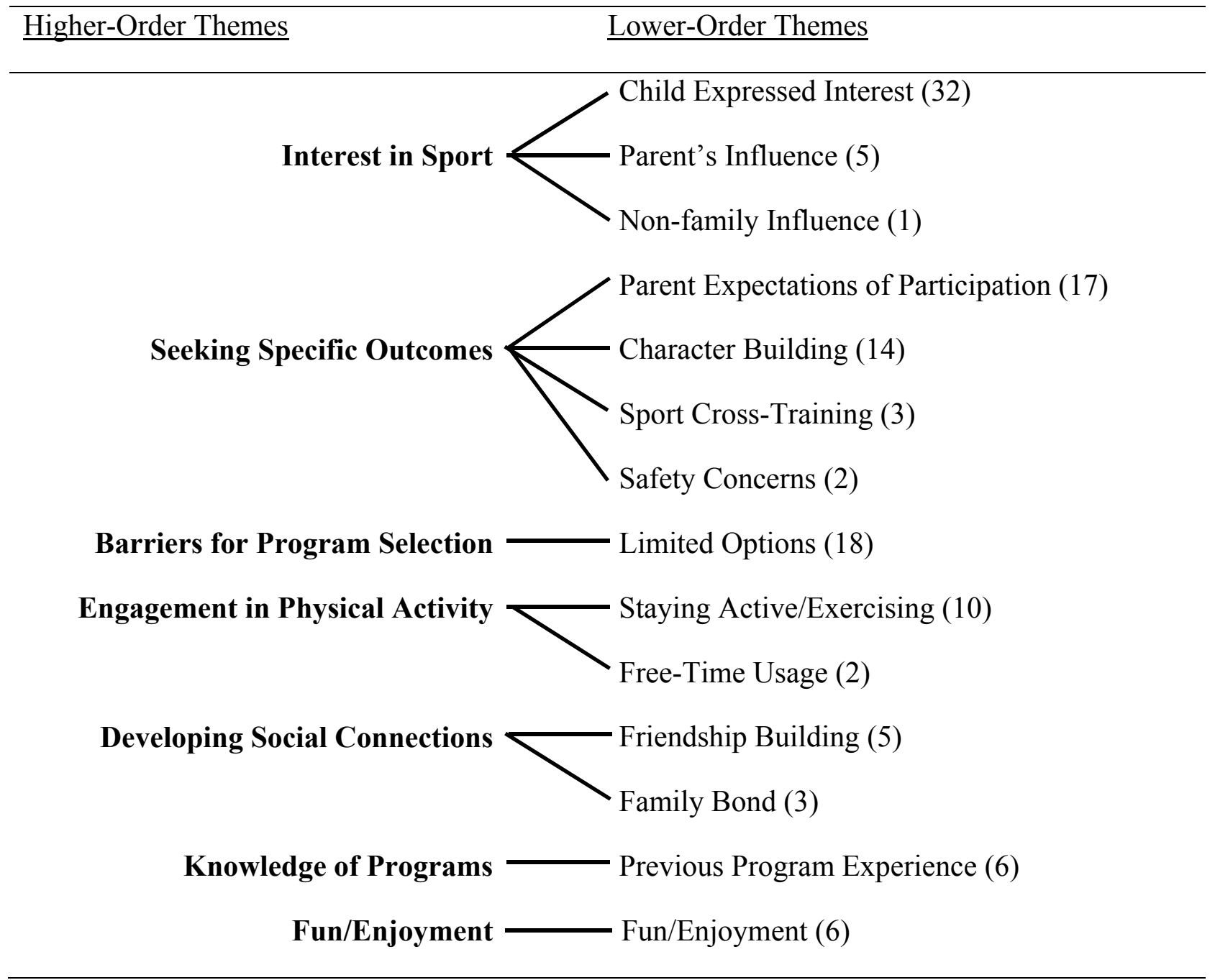




\section{Appendix L}

Top Responses Ranked as the Most Influential Factor for Youth Sport Program Selection

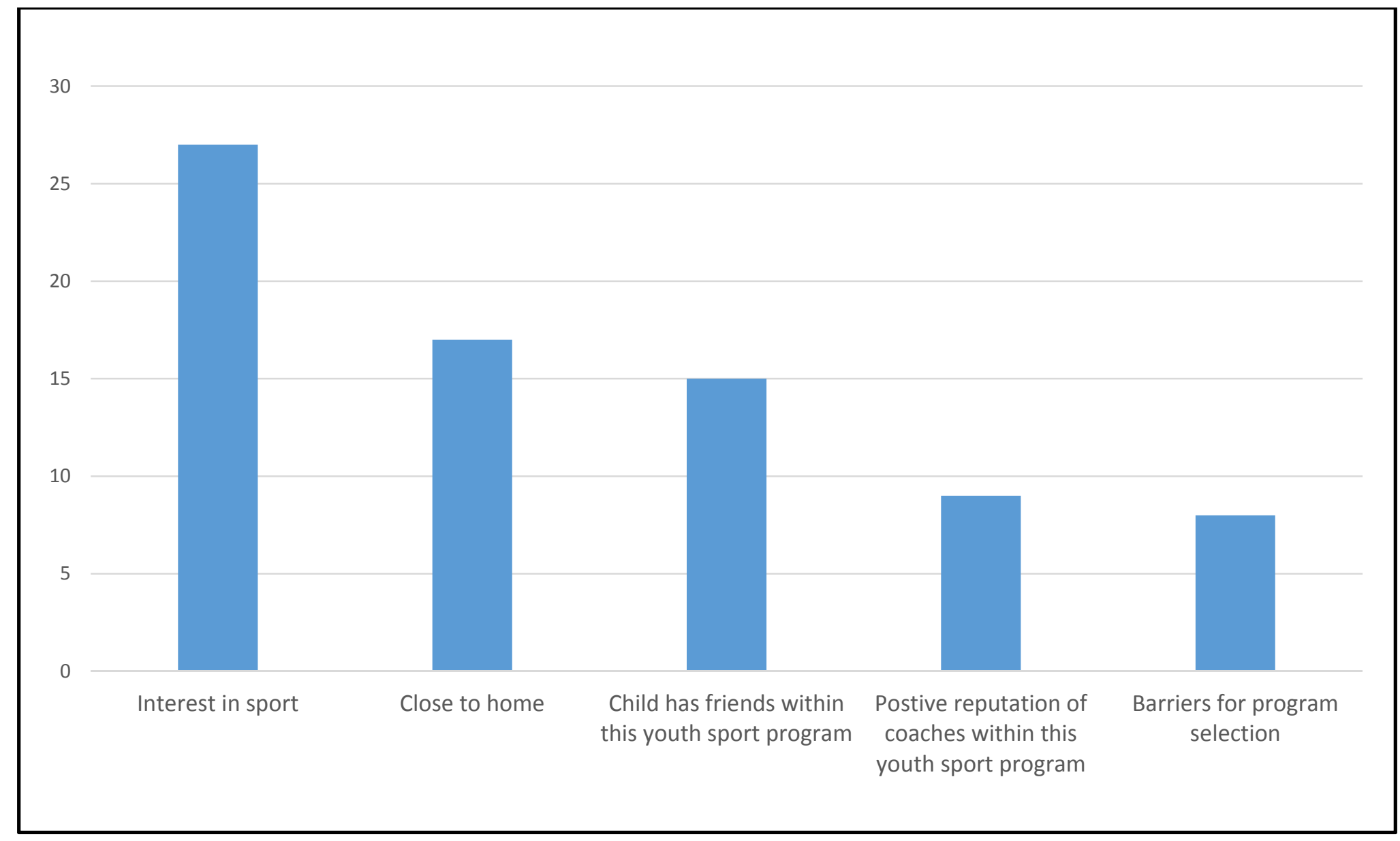

